\title{
Optimal Ranking Regime Analysis of U.S. Summer Temperature and Degree-Days: 1895-2015 $\mathcal{O}$
}

\author{
STEVen A. Mauget \\ Plant Stress and Water Conservation Laboratory, U.S. Department of Agriculture Agricultural \\ Research Service, Lubbock, Texas
}

(Manuscript received 9 March 2018, in final form 18 July 2018)

\begin{abstract}
The optimal ranking regime (ORR) method was applied to mean summer maximum $\left(\mathrm{TMX}_{S}\right)$ and mean summer minimum $\left(\mathrm{TMN}_{S}\right)$ temperature and to cumulative summer cooling degree-days $\left(\mathrm{CDD}_{S}\right)$ calculated from U.S. climate-division data during $1895-2015 . \mathrm{CDD}_{S}$ is proposed as a proxy for growing degree-days for summer corn given their high rank correlation in station data during 1950-2014. The TMX and $_{S} \mathrm{CDD}_{S}$ ORR analyses show similar climate-regime patterns. Western and northeastern divisions experienced multidecadal cool periods before 1930 and warm periods after 1990. The 1930s drought appears as decadal warm regimes over the Midwest and Great Plains. Multidecadal $\mathrm{TMX}_{S}$ and $\mathrm{CDD}_{S}$ temperature cycles are evident over the Southeast, but $\mathrm{TMX}_{S}$ and $\mathrm{CDD}_{S}$ variation over the Midwest's Corn Belt agricultural region has been regime free since the early $1940 \mathrm{~s}$. By contrast, $\mathrm{TMN}_{S}$ regimes consistent with centennial-scale warming trends are found over most divisions outside the Southeast. From the multidecadal regime patterns detected by the ORR analyses, the $\mathrm{TMX}_{S}, \mathrm{TMN}_{S}$, and $\mathrm{CDD}_{S}$ series of each climate division were tested for significant linear trends during 1910-2015 and 1970-2015. Significant positive TMN $_{S}$ trends during 1910-2015 are found in 48 of the 102 divisions, with some western trend magnitudes being greater than $15 \%$ of the twentieth-century climatological mean. During 1970-2015, positive TMX $_{S}$ trends are detected over 39 western and northeastern divisions, but warming $\mathrm{TMN}_{S}$ trends are evident nationally. In some cooler western divisions, positive 1970-2015 $\mathrm{CDD}_{S}$ trend magnitudes exceed $90 \%$ of the climatological mean. Consistent with the ORR analyses, Corn Belt $\mathrm{TMX}_{S}$ and $\mathrm{CDD}_{S}$ trends are insignificant during 1970-2015.
\end{abstract}

\section{Introduction}

Summer growing season climate plays an important role in U.S. agricultural production. During the summer months, rice is grown in the Mississippi River valley, the Texas Gulf Coast, and the Sacramento River valley. Upland cotton is grown in west Texas, Arizona, the Mississippi River and San Joaquin valleys, and areas of the South. The main sorghum production region includes areas of Kansas, eastern Colorado, and the southern Great Plains. The most concentrated and extensive U.S. corn and soybean production occurs over a midwestern area known as the Corn Belt (USDA 1994, 2017a). During the 2015 and 2016 growing seasons, the United States accounted for

Supplemental information related to this paper is available at the Journals Online website: https://doi.org/10.1175/JAMC-D-180063.s1.

Corresponding author: Steven A. Mauget, steven.mauget@.ars. usda.gov
$35.5 \%$ and $34.1 \%$ of global corn and soybean production, respectively (USDA 2017b), most of which was grown in this region. Remote sensing of sun-induced chlorophyll fluorescence indicates that the U.S. Corn Belt during the northern summer is one of Earth's most photosynthetically active areas (Guanter et al. 2014).

Extremes in minimum and maximum temperatures, particularly maximum temperatures, can be a key limiting factor in U.S. summer crop development. Based on regression models using county-level yield and temperature records during 1950-2005, Schlenker and Roberts (2009) found that U.S. corn, soybean, and cotton yields gradually increase as crops are exposed to increasing temperatures below the $29^{\circ}-32^{\circ} \mathrm{C}$ range, but that exposure to temperatures above that range resulted in more abruptly decreased yield. Robertson et al. (2013) applied the Schlenker and Roberts (2009) approach to Canadian yield and temperature data and found decreased yield for a range of crops when exposed to temperatures between $28^{\circ}$ and $34^{\circ} \mathrm{C}$. Ye et al. (2017) found that cumulative exposure to temperatures above 
$30^{\circ} \mathrm{C}$ decreased Kansas corn yields during 1981-2013, with a negative effect on rain-fed yields that is 2-3 times the effect on irrigated yields. Lobell et al.'s (2011) analysis of historical African corn yield and temperature records found that exposure to temperatures above $30^{\circ} \mathrm{C}$ reduced optimally rain-fed yields by $1 \%$ and drought-stressed yields by $1.7 \%$. A summary of temperature threshold yield effects for a variety of crops can be found in Luo (2011).

Although extreme temperatures during important growth phases can hinder plant development and reproduction (Wheeler et al. 2000), crop production has been shown to be linearly related to the accumulated exposure to temperatures between a base temperature and a higher temperature optimal for growth. This has led to the calculation of a derived temperature variable referred to as growing degree-days (GDD), which measures the total exposure to temperatures within that range during a growing season (e.g., Mederski et al. 1973; Peng et al. 1989; Liang et al. 1991).

Given the negative effects of high temperatures on crop production, evidence of long-term U.S. warming trends (Karl et al. 2009; Kunkel et al. 2013) leads to questions about those trends' effects on summer temperature and GDD accumulation. Ideally, work exploring these questions would be based on quality-controlled daily station data from dense meteorological networks providing continuous and long-term data records. Previous research into variation in U.S. temperature extremes has relied on daily data that have been subjected to quality-control (QC) procedures on a case-by-case basis (DeGaetano 1996; DeGaetano and Allen 2002; Peterson et al. 2008; Lee et al. 2014). Such measures are necessary over the United States, because artificial temperature shifts can be introduced by urbanization effects (Karl et al. 1988; Karl and Jones 1989), time-of-observation bias (Karl et al. 1986), and widespread shifts in instrumentation (Quayle et al. 1991). The highest-quality long-term daily dataset provided by the U.S. National Centers for Environmental Information (NCEI) is from the U.S. Historical Climatology Network (USHCN; Menne et al. 2015). The USHCN daily data are derived from a subset of U.S. cooperative station records that have undergone a series of QC checks to detect outliers, artificial recording streaks and gaps, and spatial and temporal inconsistency. However, these data have not been subjected to procedures that can identify and correct for artificial shifts in a station's temperature record relative to those of nearby stations. There is currently no daily dataset provided by the NCEI that is adjusted to correct for nonclimatic biases in long-term U.S. temperature records.

While bias-adjusted daily temperature records would be the best data resource to identify long-term variation in U.S. summer extreme temperatures and GDD, the approach here is to use the improved and bias-corrected monthly data provided by NOAA's Climate Divisional Database (nClimDiv; Vose et al. 2014). Although defined at monthly resolution, nClimDiv data are based on bias-corrected station data and provide continuous records for 344 continental U.S. climate divisions, beginning in 1895 . Monthly data are appropriate here, given the emphasis on a ranking analysis of U.S. seasonal temperature since that year. Earlier work based on applying the optimal ranking regime (ORR) method to a previous version of divisional temperature data was limited to seasonally averaged mean monthly temperatures (Mauget and Cordero 2014). The release of nClimDiv data allows for similar ORR analyses here of mean summer maximum temperature $\left(\mathrm{TMX}_{S}\right)$ and mean summer minimum temperature $\left(\mathrm{TMN}_{S}\right)$. Although this work's focus is on summer temperature variation important to agriculture, nClimDiv data do not include monthly GDD records. The dataset does provide records of monthly cooling degree-days (CDD), which is a functionally similar temperature variable that has fairly high rank correlations with GDD accumulated over the summer months. Summer CDD is considered as a summer GDD proxy here, but the ORR and trend analyses of divisional CDD records may be considered in their own right given the variable's relationship with energy demand (Sailor and Pavlova 2003).

The goal in the following is to explore variation in U.S. summer average maximum and minimum temperature and total summer CDD $\left(\mathrm{CDD}_{S}\right)$ and summer GDD $\left(\mathrm{GDD}_{S}\right)$ during 1895-2015 using the ORR time series analysis method. Section 2 describes the nClimDiv divisional climate data and the daily USHCN station data used to estimate the rank correlation of $\mathrm{CDD}_{S}$ and $\mathrm{GDD}_{S}$ during 1950-2014. Section 3 describes and demonstrates the ORR method, and section 4 presents the 1895-2015 ORR analyses of climate-division $\mathrm{TMX}_{S}$ and $\mathrm{TMN}_{S}$. Section 5a presents the $\mathrm{GDD}_{S}$ versus $\mathrm{CDD}_{S}$ rank correlations for 121 USHCN stations, and section $5 \mathrm{~b}$ presents the 1895-2015 ORR analysis for divisional $\mathrm{CDD}_{S}$. Section 6 presents the results from linear trend analyses of divisional $\mathrm{TMX}_{S}, \mathrm{TMN}_{S}$, and $\mathrm{CDD}_{S}$ series during 1910-2015 and 1970-2015. Section 7 presents a summary and discussion.

\section{Data}

The nClimDiv monthly temperature and CDD values for continental U.S climate divisions are derived from Global Historical Climatology Network-Daily station temperature data. This process begins by generating a gridded data product from station data with a climatologically aided interpolation process. The resulting gridded data are then 


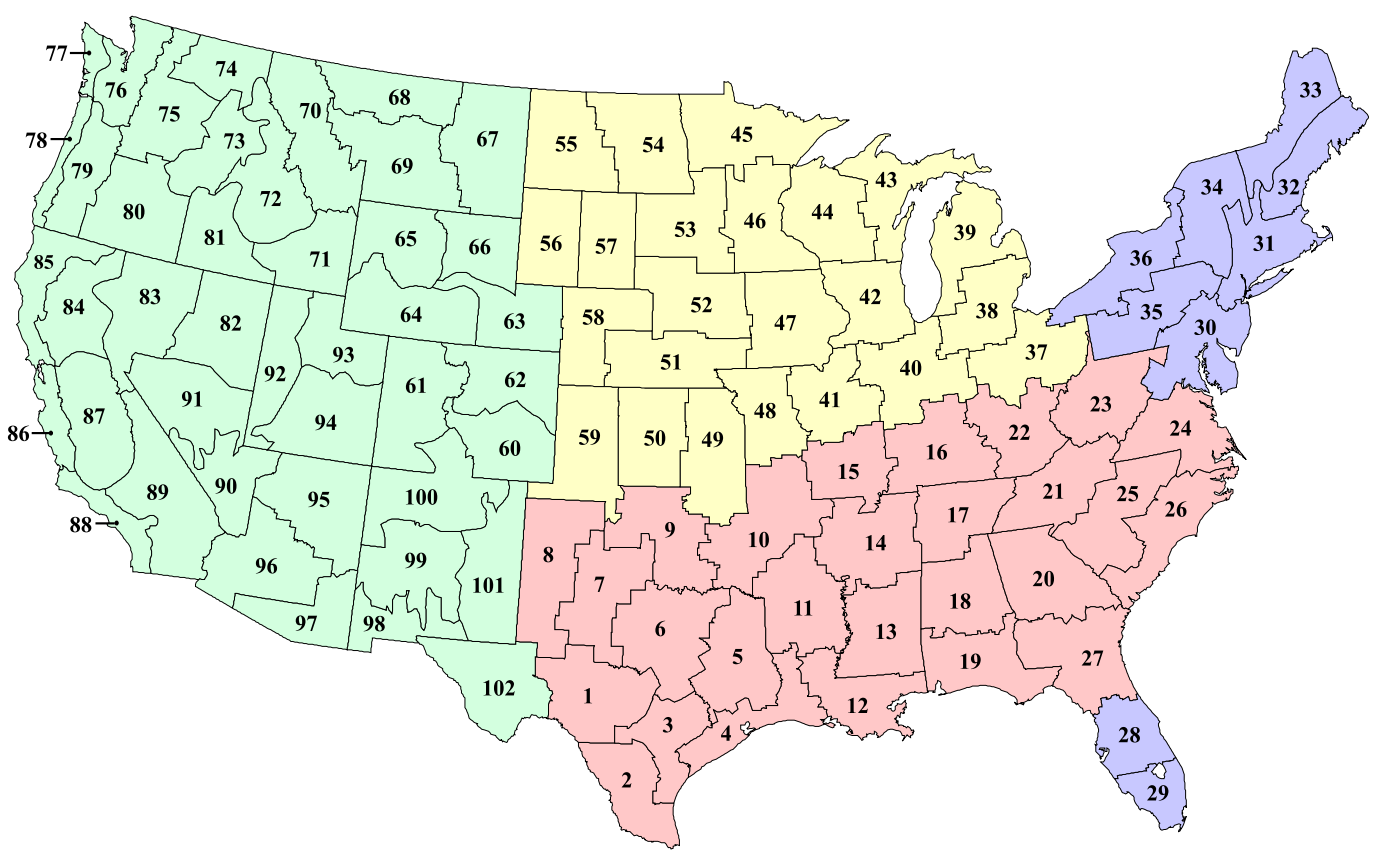

FIG. 1. Locations of the 102 U.S. climate divisions. Red, blue, yellow, and green divisions mark the southeastern, northeastern and southern Florida, midwestern, and western regions, respectively.

area weighted to produce average monthly temperatures over each climate division during 1895-2015. Relative to the previous U.S. climate-division dataset (Guttman and Quayle 1996), nClimDiv data are based on a station network with improved coverage and quality control. The underlying station data have been adjusted for time of observation bias and were also subjected to bias adjustments (Menne and Williams 2009) to correct for undocumented changes in observation time, station location and siting conditions, and temperature instrumentation. Monthly CDD data for each climate division were derived by the NCEI from divisional temperature values with the Thom $(1954,1966)$ algorithm, which estimates the monthly accumulation of daily average temperature above $18.3^{\circ} \mathrm{C}\left(65^{\circ} \mathrm{F}\right)$. Because the 344 NCEI climate divisions have an irregular spatial distribution, with a greater number of divisions defined in the eastern United States relative to the West, monthly mean minimum temperature (TMN), mean maximum temperature (TMX), and CDD values were area-weighted averaged here to the more uniform 102 "megadivision" resolution used by the U.S. Climate Prediction Center (Fig. 1). TMX $\mathrm{TM}_{S}$ and $\mathrm{TMN}_{S}$ values were calculated by averaging monthly mega-division temperatures over the June-August (JJA) period, and $\mathrm{CDD}_{S}$ was calculated by summing monthly CDD values over the JJA period.

Daily minimum and maximum temperature station data were obtained from the USHCN. As noted above, although USHCN daily data have been subjected to
QC checks, they have not been bias adjusted for nonclimatic temperature shifts. Evaluation here of Corn Belt USHCN daily station data during the summer months shows that a reduction in daily temperature range resulting from the 1980s shift to the MaximumMinimum Temperature System (Quayle et al. 1991) is particularly evident. However, the use of these data in section 5 is limited to calculating rank correlations between 121 station's $\mathrm{CDD}_{S}$ and $\mathrm{GDD}_{S}$ totals during 1950-2014. As a result, the USHCN daily data are not used as records of unbiased temperature variation but are used to estimate the rank similarity between $\mathrm{CDD}_{S}$ and $\mathrm{GDD}_{S}$ values calculated from the same temperature records.

\section{The ORR method}

Detecting variation in long-term climate records can be confounded by a time series analysis method's basic assumptions. Regional climate variability can occur in intermittent regimes or irregular cycles, but indiscriminate linear trend analysis assumes somewhat linear behavior over the periods that trends are fitted. Centennial and multidecadal global temperature records, for example, show evidence of breakpoints and piecewise linear variation with changing trend values [see Seidel and Lanzante (2004) and references therein]. Moving-window-based methods such as wavelet analysis (Lau and Weng 1995) provide a way of exhaustively sampling a time series' variation and have been 
used to resolve intermittent climate cycles (Wang and Wang 1996; Minobe et al. 2002). However, wavelet analysis and related methods (Harris 1978; Mihovilovic and Bracewell 1991) still assume that a time series' underlying behavior is basically cyclic. By contrast, ORR analysis is based on a less restrictive condition, that is, that climate variability occurs as distinct decadal to multidecadal climate regimes with arbitrary onset and duration. The method detects climate regimes as the most significant sequences of low and high rankings in a time series relative to a null hypothesis that assumes the absence of trends and low-frequency variation $\left(H_{1}\right)$. Its strengths stem from a ranking- and movingwindow-based approach that avoids the restrictive assumptions on which some time series analysis methods are based.

In short, the ORR method (Mauget and Cordero 2014; Mauget 2003, 2011, 2015) is a brute-force analysis of rankings to find the most significant sequences of low or high rankings in a time series. Given a 120 -yr time series of $\mathrm{TMN}_{S}, \mathrm{TMX}_{S}$, or $\mathrm{CDD}_{S}$ values, the method begins by ranking a time series' values and then sampling the rankings over running time windows. Each sample of rankings are converted into corresponding Mann-Whitney $U$ and $Z$ statistics (Mann and Whitney 1947), which are normally distributed variables that are proportional to the incidence of high rankings in the sample. Thus, $U$ statistics in a distribution's upper (lower) tail indicate a sample with a high incidence of high (low) rankings. This running sampling of rankings is repeated over a range of sampling sizes to test for regimes of varying length. Finally, the significant $Z$ statistics from all the running analyses are then evaluated to identify the most significant concentrations of low or high rankings, that is, optimal ranking regimes, occurring over nonoverlapping time windows.

Although the $U$ statistic for a sample of rankings can be calculated on the basis of the sample's size and rank sum (Wilks 2011), the statistic is also equal to the total number of data values outside the sampling window that precede each sample value when all values are arranged by rank (Hollander and Wolfe 1999). Thus for a 120-year time series divided into a sample window of $n_{\mathrm{I}}=20$ years and $n_{\mathrm{II}}=100$ years outside that window, the largest $U$ statistic occurs when the sample contains the 20 highest-ranked years. In that case, 100 nonsample years precede each sample year when arranged by rank, resulting in $U_{\max }=100 \times 20=2000$. The smallest $U$ statistic is produced by a sample with the 20 lowestranked years, where no sample ranking is preceded by nonsample rankings when rank ordered $\left(U_{\min }=0 \times 20\right)$. Sets of 20 randomly sampled rankings produce $U$ statistics that are normally distributed between those two extreme values. That distribution's mean is equal to the average of the $U_{\min }$ and $U_{\max }$ values:

$$
\mu_{0}=0.5[(0 \times 20)+(100 \times 20)]=0.5 n_{\mathrm{I}} n_{\mathrm{II}} .
$$

The $U$ distribution's standard deviation can be estimated with (Wilks 2011)

$$
\begin{aligned}
\sigma_{0}= & \left\{\frac{n_{\mathrm{I}} n_{\mathrm{II}}\left(n_{\mathrm{I}}+n_{\mathrm{II}}-1\right)}{12}\right. \\
& \left.-\gamma\left[\frac{n_{\mathrm{I}} n_{\mathrm{II}}}{12\left(n_{\mathrm{I}}+n_{\mathrm{II}}\right)\left(n_{\mathrm{I}}+n_{\mathrm{II}}-1\right)}\right]\right\}^{1 / 2},
\end{aligned}
$$

where

$$
\gamma=\sum_{j=1}^{J}\left(t_{j}^{3}-t\right)
$$

is a factor accounting for the incidence of ties in a time series' values, with $J$ indicating the number of groups with tied values and $t_{j}$ giving the number of tied values within each group. A sample's $U$ statistic can be $Z$ normalized using the null parameters of Eqs. (1) and (2), with significant negative (positive) $Z$ values indicating a significant incidence of low (high) rankings relative to a null hypothesis that assumes random sampling $\left(H_{0}\right)$ :

$$
Z_{0}=\frac{U-\mu_{0}}{\sigma_{0}}
$$

Although the ORR method tests for significant lowfrequency climate variability, the Monte Carlo-derived null parameters that specifically test the $H_{1}$ hypothesis in previous work (Mauget 2003, 2004) can result in $Z$ statistics that are less conservative, that is, with larger magnitudes, than those resulting from Eq. (3). To prevent assigning significance to ranking sequences consistent with random variation, the approach here was to compare the Eq. (3) $Z_{0}$ magnitude with that of a second $Z_{1}$ statistic that specifically tests the $H_{1}$ hypothesis:

$$
Z_{1}=\frac{U-\mu_{1}}{\sigma_{1}} .
$$

For each time series and each $n_{\mathrm{I}}$ sample size, the Eq. (4) $\mu_{1}$ and $\sigma_{1}$ null parameters were calculated through a Monte Carlo process that repeatedly sampled rankings from 120-yr autoregressive noise series consistent with $H_{1}$. The Monte Carlo procedure used to generate $H_{1}$-consistent $U$ null distributions and calculate their $\mu_{1}$ and $\sigma_{1}$ null parameters is described in Mauget and Cordero (2014). As in that analysis, a ranking sample's $Z$ statistic was assigned on the basis of which $Z$ normalization 
resulted in the smallest $Z$ magnitude and the most conservative significance level:

$$
|Z|=\min \left(\left|Z_{0}\right|,\left|Z_{1}\right|\right) .
$$

Figures 2a-e demonstrate the ORR procedure applied to Fig. 1's division 84 (northern California) $\mathrm{TMX}_{S}$ time series. Figure 2 a shows the $\mathrm{TMX}_{S}$ series and its low-frequency variation derived through a low-pass Lanczos filter (Duchon 1979) with a cutoff frequency of $\nu=(20 \mathrm{yr})^{-1}$. Figure 2b shows the series of Eq. (5) $Z$ statistics for $\mathrm{TMX}_{S}$ rankings sampled over running 20 -yr periods, with horizontal lines marking the $Z$ statistics' negative and positive significance at two-sided $95 \%, 99 \%$, and $99.9 \%$ confidence levels and $Z$ magnitudes $>4.0$. Figure $2 \mathrm{~b}$ also defines the shading scheme used to identify those eight $Z$ levels on the figure's left axis. Figure 2c's colored horizontal regime bars mark the duration of the 20-yr ranking regimes found to be negatively or positively significant at a $95 \%$ or better confidence level in Fig. 2b, superimposed on the $\mathrm{TMX}_{S}$ series. Those bars are vertically placed according to each ranking regime's $Z$ statistic, which is measured on the figure's right axis, and are shaded with the Fig. $2 b$ color scheme.

The ORR method identifies optimally significant and nonoverlapping sequences of data rankings by calculating $U$ and $Z$ statistics from rankings sampled over moving time windows. Those windows range here from 10 to 40 years in width. For each of the 31 window sizes, running series of $Z$ statistics like that of Fig. $2 \mathrm{~b}$ are calculated with Eq. (5) for that window size for each time series. For each running $Z$ series, the corresponding probability $p$ statistics are then subjected to Ventura et al.'s (2004) false-detection-rate procedure. This test's demonstration can be found in the appendix of Mauget (2018). In addition to testing significance of $U$ statistics calculated with a fixed sample size, $Z$ normalization also makes it possible to order the significance of $U$ statistics calculated using different sample sizes. After $Z$ normalizing the running $U$ statistics from each analysis, the positive and negative $Z$ statistics from all $31 Z$ series that pass the Ventura et al. (2004) $p$-threshold test are combined as in Fig. 2d. Within those pooled statistics, the ranking sequences that produce the highest absolute $Z$ values over nonoverlapping time periods are identified (Fig. 2e). For more details of the screening process that identifies a time series' optimally significant regimes, which is illustrated in Figs. $2 \mathrm{~d}$ and $2 \mathrm{e}$, see section 3 of Mauget and Cordero (2014).

By detecting what might be considered a basic feature of climate variation-here, summer temperature and CDD regime periods - the ORR method can identify a wide range of climate variability. In Fig. 2e, the northern
California $\mathrm{TMX}_{S}$ series shows an irregular multidecadal temperature cycle between 1900 and the mid-1950s, which is found in both the Lanczos low-pass TMX $_{S}$ trace and alternating cold (1897-1916), warm (1926-40), and cold (1941-56) ORR periods. After the mid-1950s summer maximum temperatures are relatively stationary until the late 1990s but then increase into a warm ORR period during 2000-15. Figure 3 shows additional examples of how the method can detect arbitrary climate variation. In Fig. 3a, highly significant $(|Z|>4.0)$ periods of low- and high-ranked temperatures during the early (1900-39) and late (1977-2015) years of the southern Florida (division 29) $\mathrm{TMN}_{S}$ record mark a long-term warming trend. As shown in Fig. 3b's western Colorado (division 61) $\mathrm{TMN}_{S}$ series, however, widely separated cold and warm regime periods may not always indicate a trend between those periods. Figure 3c's Southern California (division 88) $\mathrm{TMN}_{S}$ series shows an example of a "wavy trend," that is, a multidecadal cycle before the 1960s that is superimposed on a longer-term warming trend. A warming trend is also detected in Fig. 3d's northern Alabama (division 18) $\mathrm{TMN}_{S}$ series, but over a multidecadal period between a cool 1955-76 regime and a warm 1993-2015 regime.

\section{ORR analyses of $T_{M N}$ and $T M X_{S}$}

The ORR method identifies climate regimes occurring over nonoverlapping time windows. As a result, a time series' most significant regimes can be plotted on a horizontal line referred to as a $Z$ line, with the regime's positive or negative significance marked by the Fig. $2 b$ color scheme. Vertically condensing a time series's regime periods this way makes it possible to plot ORR results for numerous time series on a single graph and to identify common patterns of decadal to multidecadal variability.

Figure 4 shows the $\operatorname{TMX}_{S} Z$ lines for each of Fig. 1's 102 climate divisions during 1895-2015. Each line's vertical coordinate is assigned according to the division's number on the Fig. 1 map, which also divides the continental United States into four areas. Divisions 1-27 are located over Fig. 1's red southeastern region. Divisions 28-36 define the blue region, which includes seven northeastern divisions and two divisions in southern Florida. Divisions 37-59 define a yellow region that coincides with the major agricultural production areas of the midwestern and northern Great Plains states. Figure 4's green-shaded $Z$ lines show $\mathrm{TMX}_{S}$ regimes for divisions 60-102, which are located in the western United States, the Rocky Mountain region, and parts of the western Great Plains.

In Fig. 4, significant concentrations of low-ranked $\mathrm{TMX}_{S}$ conditions before 1930 are detected over western (Fig. 4a) and northeastern (Fig. 4b) divisions, and 

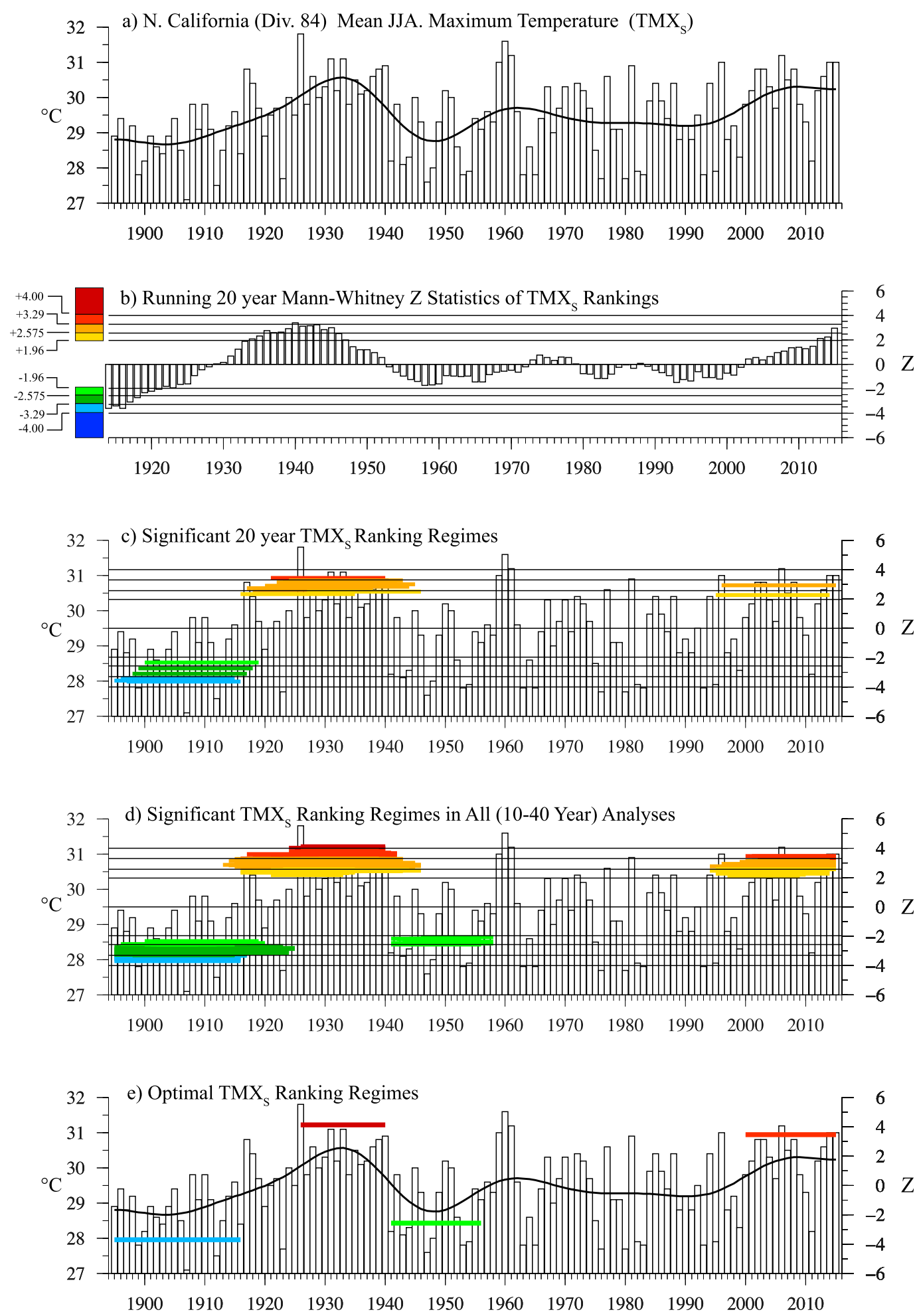

FIG. 2. (a) Summer (JJA) $\mathrm{TMX}_{S}$ record for northern California (division 84) during 1895-2015. The heavy trace shows low-frequency variation derived by using a Lanczos low-pass filter with a $\nu=(20 \mathrm{yr})^{-1}$ cutoff frequency. (b) Mann-Whitney $Z$ statistics of ranked $\mathrm{TMX}_{S}$ values sampled over running 20 -yr time windows. The horizontal lines and left-axis shading scheme show two-sided $95 \%(Z= \pm 1.96), 99 \%(Z= \pm 2.575)$, and $99.9 \%(Z= \pm 3.29)$ confidence levels and $|Z|>4.0$. (c) As in (a), but with the horizontal width of the colored bars showing the 20-yr ranking regimes in (b) with $|Z|>1.96$. The bar's vertical position shows corresponding $Z$ values as marked by the 

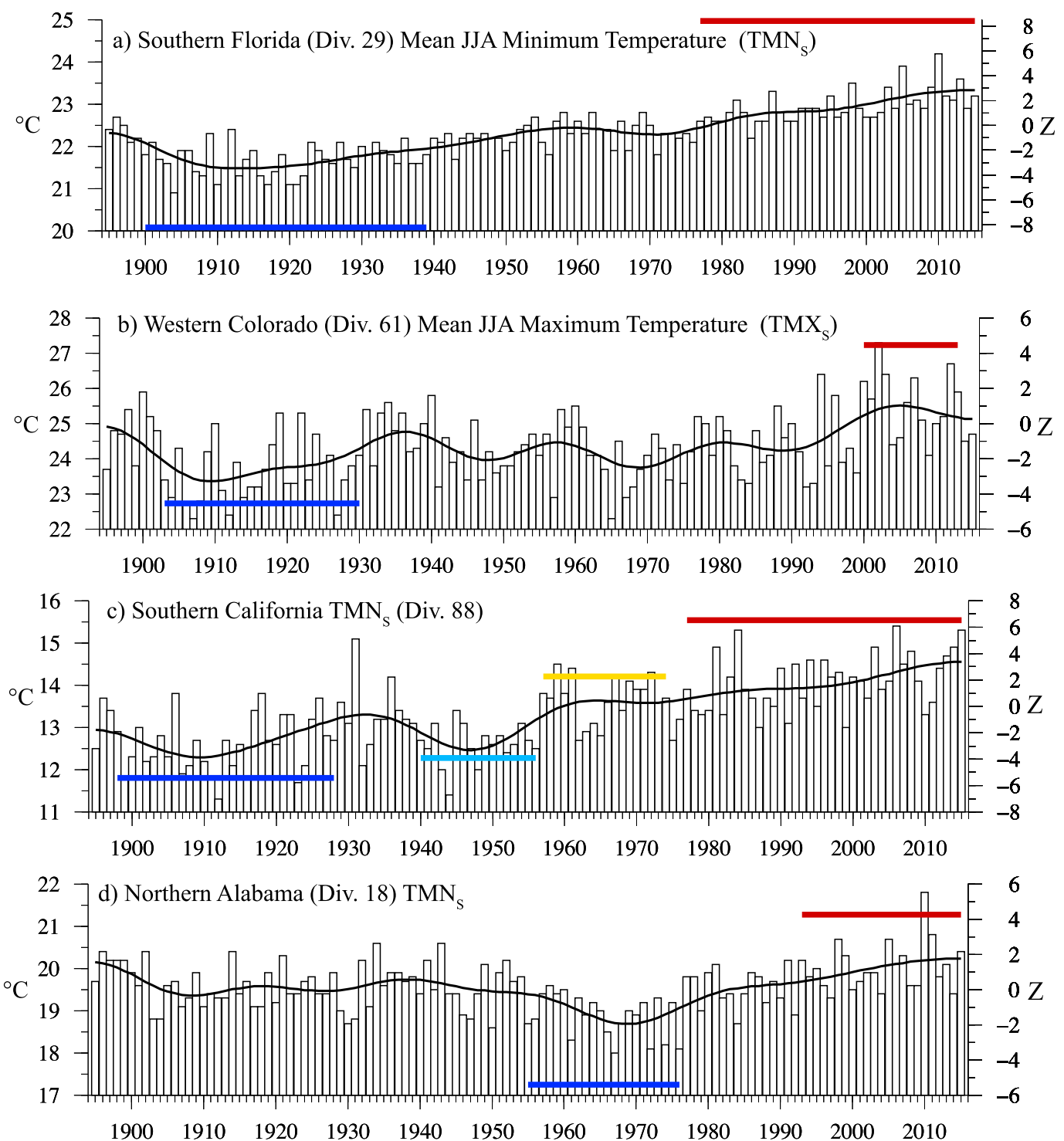

FIG. 3. As in Fig. 2e, but for (a) southern Florida (division 29) $\mathrm{TMN}_{S}$, (b) western Colorado (division 61) $\mathrm{TMX}_{S}$, (c) Southern California (division 88) $\mathrm{TMN}_{S}$, and (d) northern Alabama (division 18) $\mathrm{TMN}_{S}$.

regimes of high-ranked conditions are found after 2000 over most of those same divisions (Figs. 4c,d). In Fig. 4e, warm summers associated with the 1930s drought appear as highly significant runs of high-ranked $\mathrm{TMX}_{S}$ conditions over midwestern climate divisions 46-60, and climate divisions in the western Great Plains and interior West (divisions 63-74, 80-84). During the 1940s and 1950s, the final cool phase of Fig. 2e's pre-1960 multidecadal cycle can be seen over neighboring climate divisions 68-94 (Fig. 4f). Although summers of the 1930s were not significantly high-ranked in many of these divisions (e.g., divisions 77-80), this suggests a similar multidecadal $\mathrm{TMX}_{S}$ cycle over the western United States before 1960. Southeastern divisions 1-27 show evidence of a multidecadal $\mathrm{TMX}_{S}$ cycle, with warm regimes before the late 1950s shifting to cooler summer

right axis. (d) As in (c), but with significant $\mathrm{TMX}_{S}$ ranking regimes from ORR analyses conducted with sampling windows ranging from 10 to $40 \mathrm{yr}$. (e) The optimally significant sequences of low-ranked and high-ranked TMX occurring over nonoverlapping time windows. 


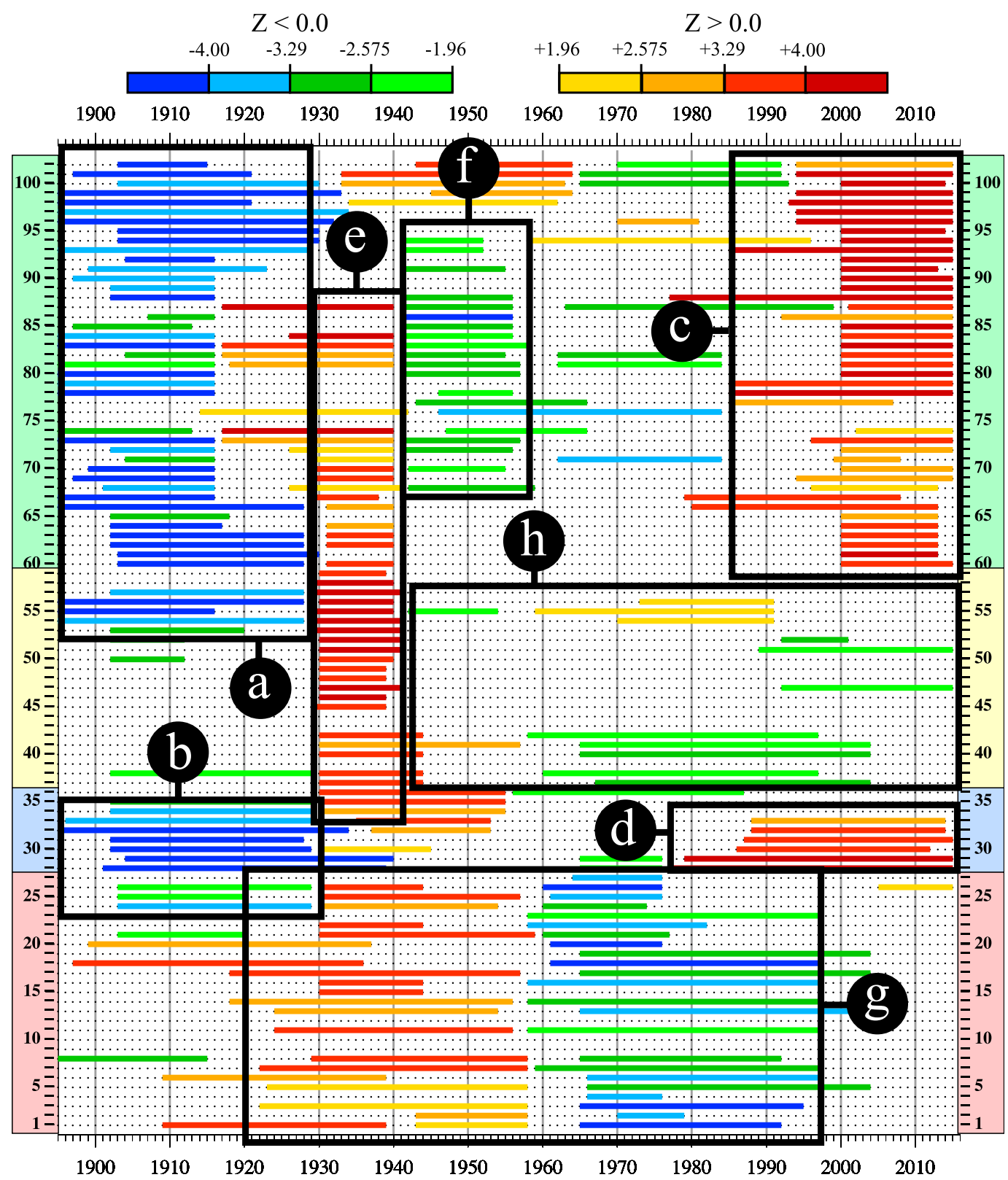

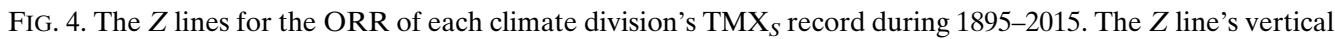
coordinates are assigned according to the Fig. 1 division numbers. Colored regions on both vertical axes mark lines for Fig. 1's four shaded regions. Positive and negative significance at $95 \%, 99 \%, 99.9 \%$ confidence levels and $|Z|>4.0$ are marked by the $Z$-scale shading scheme defined at the top. The black frames labeled with a-h outline TMX $_{S}$ regime features that are discussed in the text.

regimes during the early 1960s to mid-1990s (Fig. 4g). The latter cool regime interrupts the general twentiethcentury U.S. warming trend and as a result has been referred to a "warming hole" (Pan et al. 2004; Portmann et al. 2009; Meehl et al. 2012). In addition to the Southeast's distinctive warming-hole variation, that region shows little evidence of significant regimes of high-ranked $\mathrm{TMX}_{S}$ values after the late 1990s like those found in western and northeastern climate divisions (Figs. 4c,d). Similarly, in contrast to western, northeastern, and southeastern regime variation, over the Midwest there are no clear patterns of either high-ranked or low-ranked $\mathrm{TMX}_{S}$ regimes between the early 1940s and 2015 (Fig. 4h).

Figure 5 is Fig. 4's counterpart for mean summer minimum temperatures. When compared with Fig. 4, regime patterns consistent with long-term positive $\mathrm{TMN}_{S}$ trends 


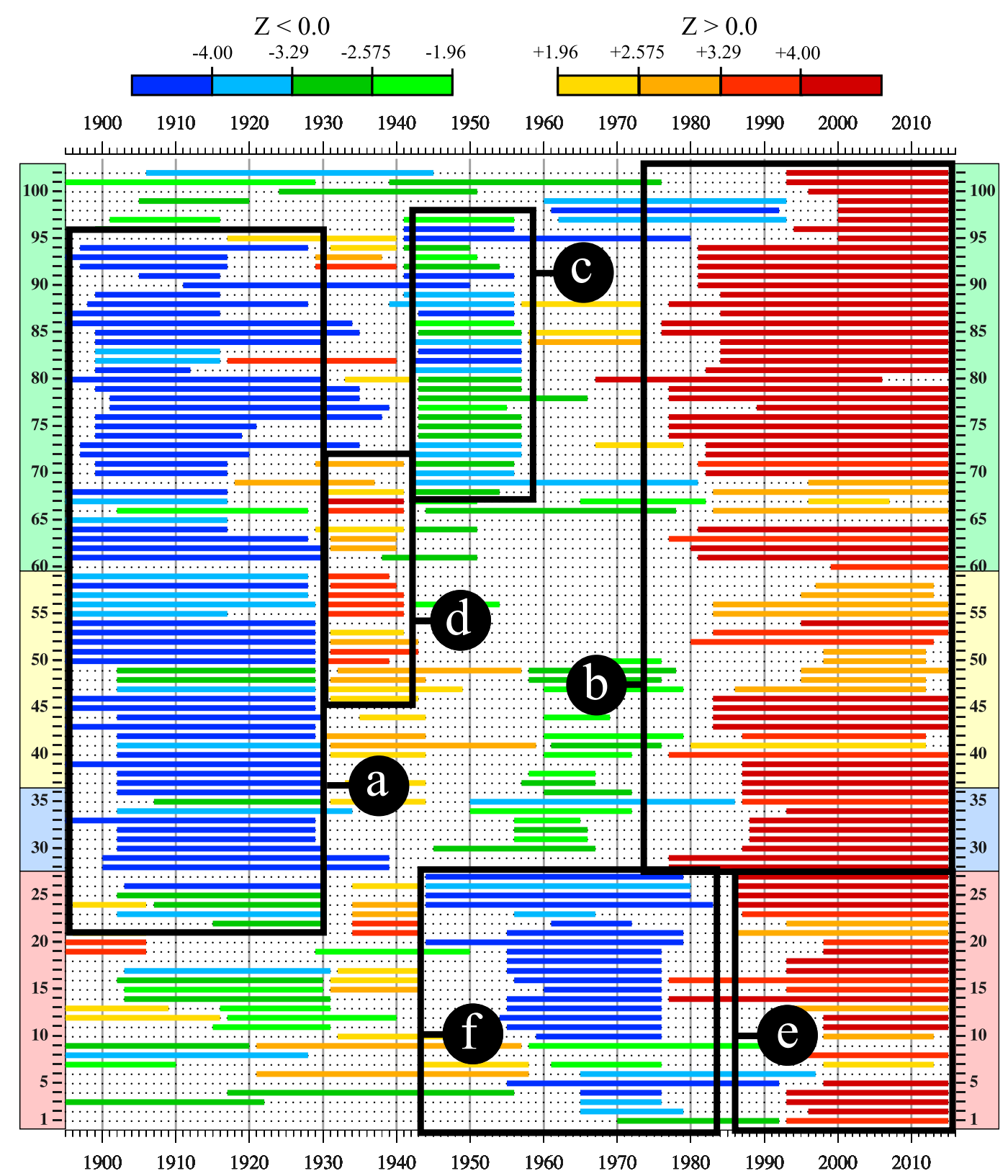

FIG. 5. As in Fig. 4, but for the ORR analyses of each division's $\mathrm{TMN}_{S}$ rankings during 1895-2015. The black frames labeled with a-f outline $\mathrm{TMN}_{S}$ regime features that are discussed in the text.

are more apparent over most of the continental United States outside the Southeast. These trends are marked by multidecadal and highly significant $(|Z|>4.0)$ regimes of low-ranked TMN ${ }_{S}$ in the early twentieth century (Fig. 5a) and similarly significant regimes of high rankings after the 1980s (Fig. 5b). Over western climate divisions 68-97, decadal cool regimes are outlined in Fig. 5c during the 1940s and 1950s. Given these division's previous cool conditions before 1930, and warm conditions after 1980, this long-term variation is consistent with the wavy trend shown in Fig. 3c's division 88 time series. Centennial $\mathrm{TMN}_{S}$ trend patterns are also found in some midwestern divisions, for example, divisions 36-39 and 43-46, where consistent $\mathrm{TMX}_{S}$ regime patterns in Fig. 4 are limited mainly to the warm 1930 s period. Similar to Fig. 4e, midwestern warm regimes are also detected in the $\mathrm{TMN}_{S}$ rankings during the 1930s (Fig. 5d), but occur at generally lower significance levels and appear over a more limited area of the Great Plains (divisions 50-60, 66-69). However, southeastern climate divisions that show almost 


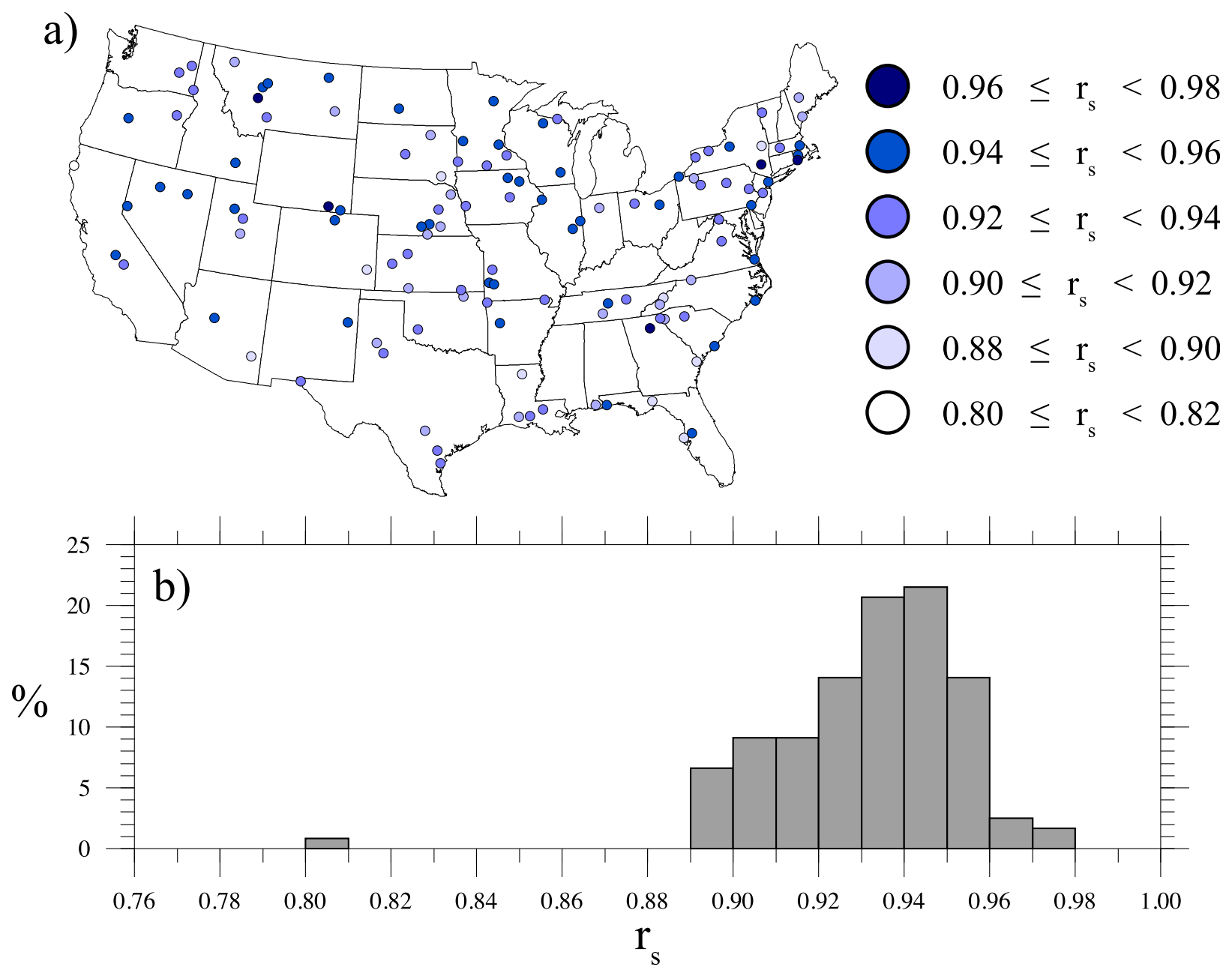

FIG. 6. (a) Spearman rank correlation values for summer (JJA) cooling degree and corn growing degree totals derived from 121 USHCN daily station temperatures during 1950-2014. (b) Histogram of the $r_{s}$ values mapped in (a).

no evidence of recent warm $\mathrm{TMX}_{S}$ conditions in Fig. 4 show a consistent pattern of warm $\mathrm{TMN}_{S}$ regimes after the mid-1990s (Fig. 5e). Relative to Fig. 4h, Fig. 5f's warming-hole southeastern cool regimes are more consistently significant, with low-ranked $\mathrm{TMN}_{S}$ conditions more concentrated from the mid-1950s to mid-1970s.

\section{Summer degree-day analysis}

Both CDD and GDD values measure the cumulative exceedance of daily average temperature above a specified base temperature $T_{b}$ over the course of daily, monthly, or seasonal time periods. The former is used to estimate electrical demand for air conditioning (e.g., Downton et al. 1988; Sailor and Pavlova 2003), and the latter estimates cumulative exposure to temperature conditions suitable for crop development (Luo 2011). The following demonstrates that the rank correlations of $\mathrm{CDD}_{S}$ and $\mathrm{GDD}_{S}$ values calculated from daily USHCN TMX and TMN values may be high enough that, for the purposes of the ORR method, the NCEI divisional CDD data might be used as a proxy for 1895-2015 GDD variation.

\section{a. GDD and CDD rank correlation}

To calculate $\mathrm{CDD}_{S}$ and $\mathrm{GDD}_{S}$ totals from the same daily temperature records, 121 stations were selected from the 1218-station USHCN network that had no more than 14 missing daily TMX or TMN values in any of the JJA periods of 1950-2014 (Fig. 6a). These stations also had no more than $1 \%$ missing JJA data over all those 65 summer seasons. Missing daily minimum and maximum temperatures were filled in with stochastically generated values (Hanson et al. 1994).

Following Lobell et al. (2013) and Ye et al. (2017), daily growing and cooling degree-days were calculated 
from interpolated hourly temperature values $T_{h}$ that were estimated by fitting 24-h cosine functions to daily TMN and TMX values:

$$
\begin{aligned}
T_{h}= & \frac{\mathrm{TMX}+\mathrm{TMN}}{2}+\frac{\mathrm{TMX}-\mathrm{TMN}}{2} \\
& \times \cos \left[\pi\left(h_{\max }-h\right) / 12\right], \quad h=1,24 .
\end{aligned}
$$

Maximum daily temperatures were assumed to occur $2 \mathrm{~h}$ before sunset $\left(h_{\max }\right)$, and a day's integer sunset hour at each station location was estimated with procedures provided in Allen et al. (1998).

As described above, cooling degrees measure the accumulation of temperature above a base temperature threshold. The CDD threshold generally coincides with the temperature at which regional electrical demand is minimized, which varies geographically (Ranson et al. 2014). This threshold $\left(T_{b \text {-cdd }}\right)$ was set to $18.3^{\circ} \mathrm{C}\left(65.0^{\circ} \mathrm{F}\right)$ in keeping with NCEI CDD calculation and previous studies (Downton et al. 1988; Sailor and Muñoz 1997; Sailor and Pavlova 2003). To calculate daily CDD values, hourly temperatures in each day's interpolated $T_{h}$ record below $18.3^{\circ} \mathrm{C}$ were first set to the $18.3^{\circ} \mathrm{C} T_{b}$ floor value:

$$
T_{h \text {-cdd }}=\max \left(T_{h}, 18.3\right) .
$$

A day's hourly $\mathrm{CDD}$ values $\left(\mathrm{CDD}_{h}\right)$ are the resulting adjusted $T_{h \text {-cdd }}$ values minus the $18.3^{\circ} \mathrm{C}$ threshold:

$$
\mathrm{CDD}_{h}=T_{h \text {-cdd }}-T_{b \text {-cdd }} .
$$

CDD values for each day of the year (doy) during JJA are the average of the day's $24 \mathrm{CDD}_{h}$ values:

$$
\mathrm{CDD}_{\text {doy }}=\frac{1}{24} \sum_{h=1}^{24} \mathrm{CDD}_{h}
$$

and $\mathrm{CDD}_{S}$, with units of accumulated degrees Celsius above the threshold temperature $\left(\mathrm{DD}_{18}\right)$, is the sum of the 1 June- 31 August daily CDD values:

$$
\mathrm{CDD}_{S}=\sum_{\mathrm{doy}=152}^{243} \mathrm{CDD}_{\mathrm{doy}} \text {. }
$$

Total $\mathrm{GDD}_{S}$ were similarly calculated for each station during 1950-2014, but with each day's hourly temperatures subjected to an additional ceiling temperature requirement. Daily growing degrees for crops are accumulated between two temperature thresholds that vary by crop (Luo 2011). Here, GDD values for each day of the summer growing season $\left(\mathrm{GDD}_{\text {doy }}\right)$ were calculated using threshold values for corn, which is the most widely produced U.S. feed grain. The corn $T_{b \text {-gdd }}$ base threshold temperature, that is, the minimum temperature required for crop development, was set to the $8^{\circ} \mathrm{C}\left(46.4^{\circ} \mathrm{F}\right)$ value assumed in Butler and Huybers (2013) and Ye et al. (2017). The corn optimum ceiling temperature, that is, the temperature above which crop development and yields are negatively impacted, was set to the $29^{\circ} \mathrm{C}$ $\left(84.2^{\circ} \mathrm{F}\right)$ value estimated by Schlenker and Roberts (2009). Thus for each day's 24 -h interpolated $T_{h}$ record, temperatures below $8^{\circ} \mathrm{C}$ were set to that $T_{b \text {-gdd }}$ floor value, and values above $29^{\circ} \mathrm{C}$ were set to a ceiling of $29^{\circ} \mathrm{C}$. A day's hourly corn GDD values $\mathrm{GDD}_{h}$ are these adjusted $T_{h}$ values $\left(T_{h \text {-gdd }}\right)$ minus the $8^{\circ} \mathrm{C}$ base threshold:

$$
\mathrm{GDD}_{h}=T_{h \text {-gdd }}-T_{b \text {-gdd }} .
$$

Similar to Eqs. (9) and (10), GDD doy values for each day of the year during JJA are the average of the day's $24 \mathrm{GDD}_{h}$ values, and total $\mathrm{GDD}_{S}$ is the sum of the 1 June-31 August GDD doy values.

Although daily $\mathrm{CDD}_{\text {doy }}$ and $\mathrm{GDD}_{\text {doy }}$ values are calculated with different base temperatures, and $\mathrm{CDD}_{\text {doy }}$ calculation has no ceiling temperature threshold, the $\mathrm{CDD}_{S}$ and $\mathrm{GDD}_{S}$ records for most of Fig. 6a's stations have fairly high rank correlations during 1950-2014. To show the agreement between both variables' rank ordering, Fig. 6a maps the Spearman rank correlation $r_{s}$ calculated from each station's $65 \mathrm{CDD}_{S}$ and $\mathrm{GDD}_{S}$ rankings during that time, and Fig. $6 \mathrm{~b}$ is a histogram showing the $r_{s}$ distribution. Of the $121 r_{s}$ values, 111 $(92 \%)$ are greater than 0.90 , with 85 values $(70 \%)$ in the $0.92-0.96$ range. Of the $10 r_{s}$ values that are less than $0.90,9$ are greater than 0.89 . Given these generally high rank correlations, ORR analyses that are based on $\mathrm{CDD}_{S}$ rankings derived from available NCEI divisional data should be qualitatively similar to analyses of $\mathrm{GDD}_{S}$. The use of $\mathrm{CDD}_{S}$ as a $\mathrm{GDD}_{S}$ proxy here does not require these variables to be quantitatively similar but does require ordinal similarity. ORR analyses conducted on the $\mathrm{GDD}_{S}$ and $\mathrm{CDD}_{S}$ rankings of Fig. 6a's stations on the basis of running 10-25-yr windows during 1950-2014 (Figs. S1, S2, and S3 in the online supplemental material) show that this is generally the case. As a result, the Fig. 7 analysis of $\mathrm{CDD}_{S}$ derived from divisional data may also be broadly representative of $\mathrm{GDD}_{S}$ variation during 1895-2015.

\section{b. ORR analyses of $C D D_{S}$}

Figure 7 plots the $Z$ lines for each climate division's $\mathrm{CDD}_{S}$ rankings. When compared with the ORR analyses of $\mathrm{TMX}_{S}$ and $\mathrm{TMN}_{S}$ in Figs. 4 and 5, the patterns of $\mathrm{CDD}_{S}$ variability closely follow those of $\mathrm{TMX}_{S}$. As in Fig. 4, low-ranked $\mathrm{CDD}_{S}$ conditions are detected over western (Fig. 7a) and northeastern (Fig. 7b) climate divisions before 1930. High-ranked conditions are also 


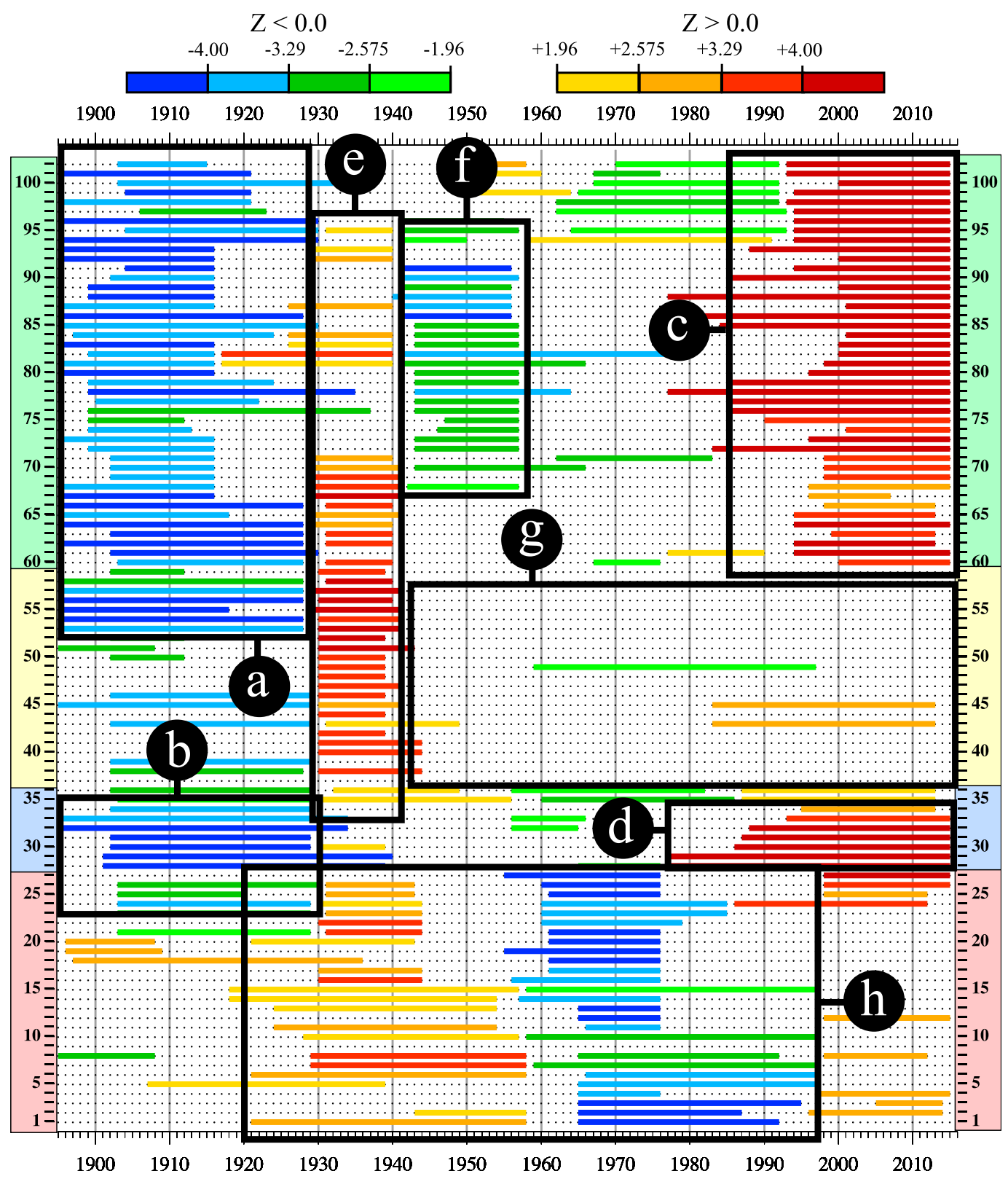

FIG. 7. As in Fig. 4, but for the ORR analyses of each division's $\mathrm{CDD}_{S}$ rankings during 1895-2014. The black frames labeled with a-h outline $\mathrm{CDD}_{S}$ regime features that are discussed in the text.

found after 1980 over most of those same divisions (Figs. 7c,d). The warm summers of the 1930s produced highly significant concentrations of both $\mathrm{TMX}_{S}$ (Fig. 4e) and $\mathrm{CDD}_{S}$ (Fig. 7e) over the northern Great Plains (divisions 51-59). Over the West, alternating periods of cool conditions before 1930 (Fig. 7a), warm conditions over divisions 81-84 in northern California and Nevada during the 1930s (Fig. 7e), and cool regimes during the 1940s and 1950s (Fig. 7f) are similar to the cyclic TMX regime patterns of Figs. 4a, 4e, and 4f. However, over
Fig. 7c's western climate divisions, the onset years of recent warm $\mathrm{CDD}_{S}$ periods tend to precede those of the warm $\mathrm{TMX}_{S}$ regimes in Fig. 4c. In Fig. 7e, sequences of high-ranked $\mathrm{CDD}_{S}$ mark the warm summers of the 1930s, but with effects more concentrated in the Great Plains (divisions 44-60 and 62-71). The southeastern multidecadal temperature cycle in Fig. $4 \mathrm{f}$ is also evident in $\mathrm{CDD}_{S}$ in Fig. 7f, but with more consistent effects of the warming-hole period during the 1960s and 1970s. Last, as in Fig. 4g, there is a conspicuous lack of 
significant $\mathrm{CDD}_{S}$ ranking regimes over the midwestern climate divisions between 2015 and the 1930s drought period (Fig. 7g).

\section{Linear trend analyses for 1910-2015 and 1970-2015}

In Figs. $5 \mathrm{~b}$ and $5 \mathrm{e}$, significant warm $\mathrm{TMN}_{S}$ regimes are almost uniformly found over the continental United States after 1980. In some divisions in the West (e.g., divisions 70-94), southern Florida (divisions 28 and 29), the Northeast (e.g., divisions 30-36), and the Midwest (divisions 37-39,43-46), these regimes are multidecadal and highly significant $(Z>4.0)$. Before 1930 , many of those same divisions show extended and similarly significant cool regimes that are roughly centered on the year 1910 in Fig. 5a, which can indicate centennial-scale warming trends (e.g., Fig. 3a,c). But over southeastern climate divisions, the cold and warm $\mathrm{TMN}_{S}$ regimes of Figs. $5 \mathrm{f}$ and $5 \mathrm{e}$ suggest a more recent warming trend since the 1970s. In contrast to the recent warmth in minimum summer temperature over almost all of the United States, warm $\mathrm{TMX}_{S}$ and $\mathrm{CDD}_{S}$ ORR periods after 1980 are limited to Fig. 1's western (Figs. 4c and 7c) and northeastern climate divisions (Figs. $4 \mathrm{~d}$ and $7 \mathrm{~d}$ ). Over southeastern divisions 1-27, there is relatively little evidence of either $\mathrm{TMX}_{S}$ or $\mathrm{CDD}_{S}$ warm regimes after 1990 in Figs. 4 and 7. To show the location and magnitudes of possibly significant centennial summer warming trends, Figs. 8a-c map the normalized linear trends of $\mathrm{TMN}_{S}, \mathrm{TMX}_{S}$, and $\mathrm{CDD}_{S}$ during 1910-2015. To estimate the magnitudes of more current trends, Figs. 8d-f map similarly normalized trends for 1970-2015. The following description of the significance test for linear trends assumes a 1910-2015 trend analysis.

Trend significance was determined following Ebisuzaki's (1997) Monte Carlo-based method. This approach estimates the significance of linear trends in four steps:

1) Detrend the 1910-2015 time series and calculate its Fourier transform.

2) Using the resulting Fourier amplitudes and a randomized phase value, generate a noise series with the same duration, mean, and variance as the detrended data series by using the inverse transform and calculate its linear trend.

3) Repeat the second step 10000 times to calculate 10000 null trend values consistent with trendless variation.

4) Given the mean and standard deviation of the step-3 null statistics, normalize the undetrended series 19102015 linear trend into corresponding $Z$ and $p$ statistics.

The $p$ values resulting from each of the 102 climate division's trends were subjected to the $p$-ranking procedure of Ventura et al. (2004), which limits the false discovery rate (FDR) in the 102 tests to no greater than $5 \%$. The test limits the FDR, that is, the percentage of significant trend values that are falsely rejected, by imposing lower and more restrictive $p$ thresholds to determine significance. For an FDR of 5\%, these $p$ thresholds are less than 0.05 . For a more in-depth explanation and demonstration of this test, see Ventura et al. (2004) or Wilks (2016).

For the $\mathrm{TMX}_{S}, \mathrm{TMN}_{S}$, and $\mathrm{CDD}_{S}$ trends during 19102015, the $p$-ranking procedure set $p$ thresholds of 0.012 , 0.022 , and 0.016 , respectively. The same thresholds for the 1970-2015 trend analyses were $0.018,0.038$, and 0.032 . To normalize significant trend magnitudes from divisions with widely different summer temperature climates, trend magnitudes were divided by the variable's twentieth-century climatological mean $C_{20 \mathrm{C}}$. A trend's 1910-2015 magnitude is measured as the difference between a significant linear trend line's 2015 $\left(T_{2015}\right)$ and $1910\left(T_{1910}\right)$ values. Thus the normalized 1910-2015 trends $\tau_{1910}$ are those magnitudes, divided by the variable's $1901-2000$ mean $C_{20 \mathrm{C}}$ :

$$
\tau_{1910}=100.0 \frac{T_{2015}-T_{1910}}{C_{20 \mathrm{C}}} .
$$

Likewise, normalized $1970-2015$ trends $\tau_{1970}$ are the 1970-2015 trend magnitude divided by the twentiethcentury mean:

$$
\tau_{1970}=100.0 \frac{T_{2015}-T_{1970}}{C_{20 \mathrm{C}}} .
$$

Figures 8a-c map the divisional $\tau_{1910}$ values for $\mathrm{TMX}_{S}$, $\mathrm{TMN}_{S}$, and $\mathrm{CDD}_{S}$, and Figs. 8d-f map those variables' $\tau_{1970}$ values. Figures $8 \mathrm{~g}-\mathrm{i}$ map each variable's twentiethcentury mean.

In Fig. 8a, positive $\tau_{1910}$ values for $\mathrm{TMX}_{S}$ range from $2.5 \%$ (division 28 ) to $6.5 \%$ (division 94 ), with significant trends found in the Southwest and interior West, Florida, and the northeastern seaboard. Significant negative $\tau_{1910}$ trends between $-4.8 \%$ and $-3.7 \%$ are found in five midwestern divisions. These are the only significant negative trends found in all three variables during either 1910-2015 or 1970-2015. Of 102 climate divisions, only 24 show significant TMX $_{S}$ trends of either sign. In Fig. 8b, 48 of 102 climate divisions show significant positive $\mathrm{TMN}_{S}$ trends during $1910-2015$. Significant $\mathrm{TMN}_{S}$ trends are found in the West and interior West, climate divisions adjacent to the Great Lakes and in the Northeast, and in southern Florida. The largest $\mathrm{TMN}_{S} \tau_{1910}$ value $(23.0 \%)$ is found in western Colorado (division 86). Other $\mathrm{TMN}_{S}$ $\tau_{1910}$ values of greater than $17.6 \%$ are found in Idaho (division 72), Washington (division 76), Oregon (division 80), and California (division 86). Twenty-five climate 
JJA Maximum Temperature JJA Minimum Temperature

JJA Cooling Degree Days
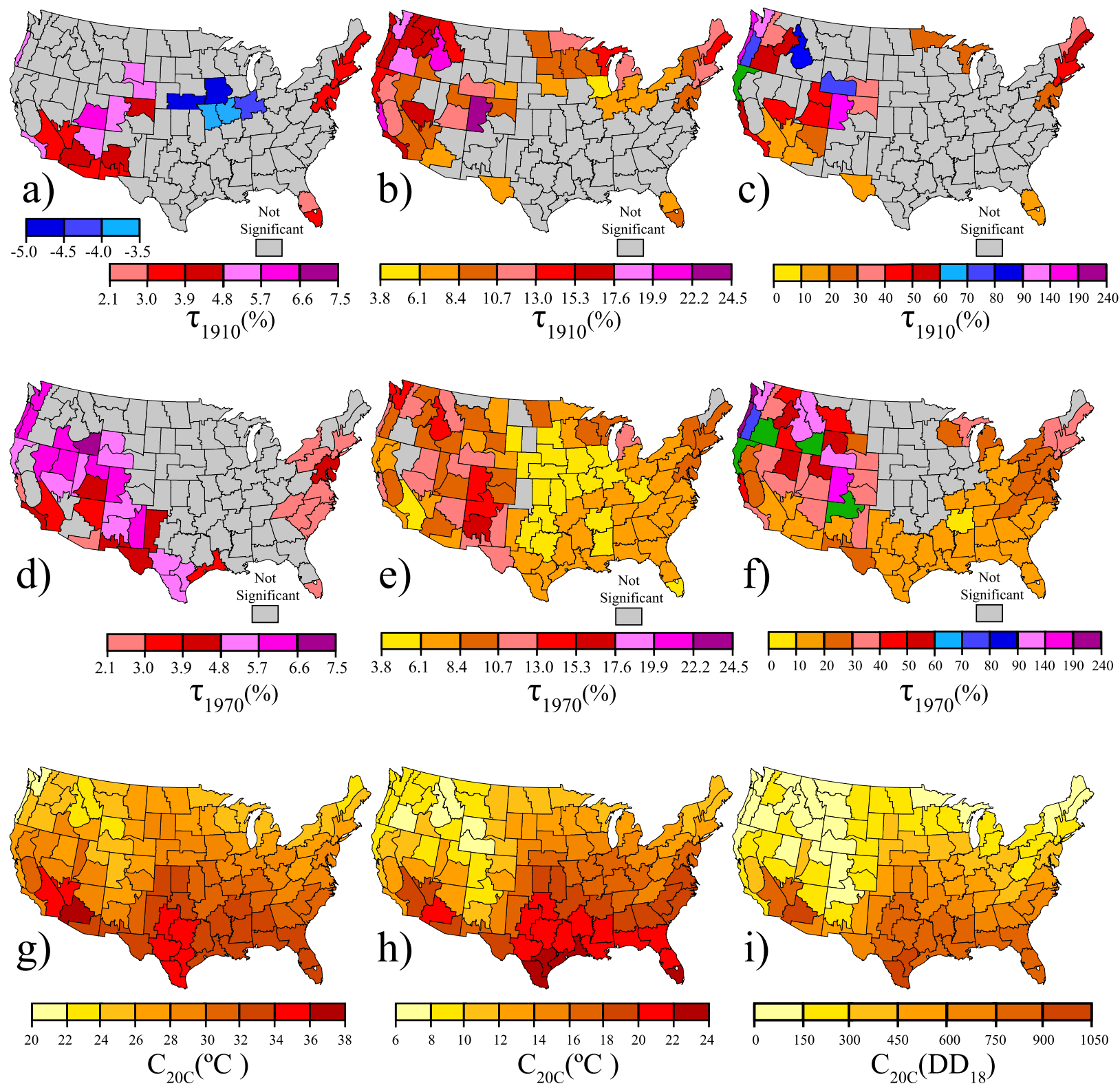

FIG. 8. Normalized 1910-2015 linear trends for (a) JJA TMX, (b) JJA TMN, and (c) cumulative JJA CDD, and normalized 1970-2015 linear trends for (d) JJA TMX, (e) JJA TMN, and (f) cumulative JJA CDD; gray-shaded divisions mark insignificant trends. Also shown is the 1901-2000 climatology of (g) mean JJA maximum temperature, (h) mean JJA minimum temperature, and (i) cumulative JJA CDD.

divisions in the West, Midwest, and Northeast have $\tau_{1910}$ trends above $10.7 \%$.

In Fig. 8c, significant $\tau_{1910}$ values for $\mathrm{CDD}_{S}$ vary between $13.5 \%$ (west Texas division 102) and $189.2 \%$ (the Oregon coast division 78). Note that Figs. $8 \mathrm{c}$ and $8 \mathrm{f}$ 's scales are nonlinear, with $10 \%$ increments below $90 \%$ and $50 \%$ increments above $90 \%$. Other western climate divisions with $\tau_{1910}$ values above $90 \%$ include Washington state divisions 76 and 77 and western Colorado division 61.
These are regions with low $C_{20 \mathrm{C}}$ values $\left(<150 \mathrm{DD}_{18}\right)$ in Fig. 8i, which indicates large $\mathrm{CDD}_{S}$ trends during 1910 2015 relative to low climatological means. Other divisions with proportionately large $\mathrm{CDD}_{S}$ trends $\left(\tau_{1910}>70 \%\right)$ include divisions in Oregon (division 79), Idaho (division 72), and Wyoming (division 64).

In Fig. 8d, normalized 1970-2015 $\mathrm{TMX}_{S}$ trends vary from $2.3 \%$ (southern Florida division 29) to $7.5 \%$ (Idaho division 71). When compared with Fig. 8a's pattern of 
positive $\tau_{1910}$ values for $\mathrm{TMX}_{S}$, there is more consistent evidence of larger 1970-2015 TMX $_{S}$ trend magnitudes in Fig. 8 d. In the former, there are 7 interior western climate divisions with $\tau_{1910}$ values above $4.8 \%$; in the latter, there are 20 divisions between southern Texas and the Pacific Northwest with $\tau_{1970}$ above that value. By contrast, Eastern Seaboard and Florida climate divisions with significant positive $\mathrm{TMX}_{S}$ trends after 1970 show $\tau_{1970}$ values that are below $4.8 \%$.

In Fig. 8e, consistent with the nearly nationwide shift to warm $\mathrm{TMN}_{S}$ regimes after the early 1980s (Figs. 5b,e), significant positive $\mathrm{TMN}_{S}$ trends are found in 95 of the 102 divisions during 1970-2015. The corresponding $\tau_{1970}$ values vary from $3.9 \%$ (eastern Iowa division 47 ) to $15.6 \%$ (New Mexico division 99). Similar to the higher $\tau_{1970}$ percentages for $\mathrm{TMX}_{S}$ in Fig. $8 \mathrm{~d}$, almost all of the largest $(>10.7 \%)$ values for $\mathrm{TMN}_{S}$ in Fig. $8 \mathrm{e}$ are found in climatologically cooler $\left(\mathrm{TMN}_{S} C_{20 \mathrm{C}}<10^{\circ} \mathrm{C}\right)$ divisions along the Pacific coast, in the Pacific Northwest, and in the interior West. By contrast, Great Plains and midwestern divisions to the east show relatively weak $(<6.1 \%) \tau_{1970}$ values for $\mathrm{TMN}_{S}$.

In Fig. 8f, significant $\tau_{1970}$ values for $\mathrm{CDD}_{S}$ vary from $9.4 \%$ (the southern division 14 ) to $219.7 \%$ (the Oregon coast division 78). As in Fig. 8c, the lowest (highest) $\tau_{1970}$ values tend to occur over divisions with the highest (lowest) $C_{20 \mathrm{C}}$ values in Fig. 8i. Thus, over southern climate divisions with twentieth-century mean $\mathrm{CDD}_{S}$ values $>750 \mathrm{DD}_{18}, \tau_{1970}$ values are generally less than $20 \%$. As mean $\mathrm{CDD}_{S}$ decreases in mid-Atlantic, Great Lakes, and northeastern climate divisions, $\tau_{1970}$ values increase into the $20 \%-40 \%$ range. This inverse relationship is most clear over climate divisions along the northwestern Pacific coast and high-elevation divisions in the interior West with low climatological $\mathrm{CDD}_{S}$ values. Thus, for example, the twentieth-century climatological mean for division 78 is $13.0 \mathrm{DD}_{18}\left({ }^{\circ} \mathrm{C}\right)$, while the linear trend's magnitude, that is, $T_{2015}-T_{1970}$, is $28.7^{\circ} \mathrm{C}$. During JJA, 2014 and 2015 total $\mathrm{CDD}_{S}$ for that climate division rose to 63.3 and $72.8 \mathrm{DD}_{18}$, the two highest values for $1895-2015$. Over western Colorado division $61\left(\tau_{1970}=161.4 \%\right)$, the $C_{20 \mathrm{C}}$ mean is $27.6 \mathrm{DD}_{18}$ and the linear trend's rise during $1970-2015$ is $44.5^{\circ} \mathrm{C}$. The 10 most highly ranked $\mathrm{CDD}_{S}$ values for that climate division during 1895-2015, which varied between 65.6 and $120.6 \mathrm{DD}_{18}$, occurred after 1993.

\section{Summary and discussion}

To identify trends and decadal to multidecadal regimes in mean summer (JJA) $\mathrm{TMX}_{S}, \mathrm{TMN}_{S}$, and cumulative $\mathrm{CDD}_{S}$, the ORR time series analysis method (section 3) was applied to U.S. climate-division data during 1895-2015. Given the generally high rank correlation with summer growing degree-day totals for corn estimated from station data during 1950-2014 (section $5 \mathrm{a})$, the $\mathrm{CDD}_{S}$ variation found here in the divisional data is proposed as a proxy for divisional $\mathrm{GDD}_{S}$ variation during 1895-2015.

The ORR analyses of $\mathrm{TMX}_{S}$ (Fig. 4) and $\mathrm{CDD}_{S}$ (Fig. 7) show generally similar variation. Early twentieth-century cool regimes are found over divisions in the West, the Northeast, and Florida (Figs. 4a,b and 7a,b), whereas most of those same divisions experienced warm regimes after 1990 (Figs. 4c,d and 7c,d). These are regions where U.S. divisional summer mean temperatures were significantly correlated with Northern Hemisphere summer temperatures during 1896-2012 according to Mauget and Cordero (2014). Thus this long-term temperature variation appears to be the U.S. expression of broader hemispheric variability. Both $\mathrm{TMX}_{S}$ and $\mathrm{CDD}_{S}$ show a low-frequency multidecadal cycle over the southeastern United States (Figs. 4h and 7h) associated with twentiethcentury warming-hole variation (Portmann et al. 2009; Meehl et al. 2012; Mauget and Cordero 2014). Over the Midwest, however, both the $\mathrm{TMX}_{S}$ and $\mathrm{CDD}_{S}$ analyses (Figs. $4 \mathrm{~g}$ and $7 \mathrm{~g}$ ) show a near absence of significant summer warm or cold regimes since the 1930s drought period (Figs. 4e and 7e).

By contrast, the TMN ${ }_{S}$ ORR analyses (Fig. 5) show evidence of centennial-scale warming trends in most climate divisions outside the southeastern United States. This consists of highly significant $(|Z|>4.0)$ multidecadal periods of low-ranked $\mathrm{TMN}_{S}$ in the early twentieth century (Fig. 5a) and high-ranked regimes of similar duration and significance after 1980 (Fig. 5b). Over the Southeast, the warming hole's cool regime is apparent during the 1950s, 1960s, and 1970s (Fig. 5f). However, although the $\mathrm{TMX}_{S}$ and $\mathrm{CDD}_{S}$ analyses of Figs. 4 and 5 show little evidence of recent southeastern warmth, warm $\mathrm{TMN}_{S}$ regimes are evident over the Southeast after the early 1980s (Fig. 5e).

Linear trend analyses of the three temperature variables during 1910-2015 and 1970-2015 are generally consistent with the regime patterns that are seen in Figs. 4, 5, and 7. Although significant positive $\mathrm{TMX}_{S}$ trends are found in the West, the Northeast, and Florida during 1910-2015 (Figs. 8a), positive $\mathrm{TMN}_{S}$ trends over that period (Fig. 8b) are more consistently evident in those regions and in Midwest and Great Lakes climate divisions. Relative to twentieth-century climatology (Figs. 8g,h), the magnitudes of 1910-2015 $\mathrm{TMN}_{S}$ trends [Eq. (12)] generally exceed those of $\mathrm{TMX}_{S}$. In Fig. 8a, the largest TMX trend magnitude as a percentage of climatology is $6.5 \%$; in Fig. 8 b, the largest $\mathrm{TMN}_{S}$ trend magnitude is $23.0 \%$. Over northwestern and interior West climate 
divisions with low ( $\left.<150 \mathrm{DD}_{18}\right)$ mean twentieth-century $\mathrm{CDD}_{S}$ values (Fig. 8i), the 1910-2015 $\mathrm{CDD}_{S}$ trend magnitudes exceed $70 \%$ of climatology (Fig. 8c). The $\mathrm{CDD}_{S}$ trend magnitudes for climate divisions along the Oregon and Washington coasts are $189.2 \%$ and $179.5 \%$ of climatology, respectively.

The normalized TMX $_{S}$ trend magnitudes for 1970-2015 [Eq. (13)] show significant positive trends over the West and Texas, Florida, and Eastern Seaboard climate divisions (Fig. 8d). Relative to 1910-2015 TMX $_{S}$ trends, positive $\mathrm{TMX}_{S}$ trends since 1970 are more consistently present between southern Texas and the Northwest and have larger magnitudes $(4.8 \%-7.5 \%)$. However, 63 of the 102 climate divisions, including midwestern and Great Plains agricultural divisions, show insignificant $\mathrm{TMX}_{S}$ trends after 1970.

Consistent with the nearly national evidence of warm $\mathrm{TMN}_{S}$ regimes after 1980 (Figs. 5b,e), 95 of the 102 climate divisions show significant positive $\mathrm{TMN}_{S}$ trends during 1970-2015 (Fig. 8e). Like the 1970-2015 TMX TM $_{S}$ trends, the largest $\mathrm{TMN}_{S}$ magnitudes as a percentage of climatology are found in the interior West and the Northwest. During 1970-2015, significant positive CDD $S$ trends are found in 79 of 102 climate divisions, with insignificant trends in the northern Great Plains, the Midwest, and northern Maine (Fig. 8f). Like the 1910-2015 $\mathrm{CDD}_{S}$ trends, the more recent $\mathrm{CDD}_{S}$ trend magnitudes in some western divisions are substantial $(>90 \%)$ relative to climatology.

The summer temperature trends found here are consistent with previous work that has found greater warming in U.S. minimum temperatures relative to maximum temperatures (Karl et al. 1993; Gallo et al. 1999; Lee et al. 2014). The proposed causes for this differential warming include changes in cloudiness, cloud cover height, atmospheric water vapor, aerosol loading, and atmospheric circulation (Karl et al. 1984, 1988; Vose et al. 2005). Warming in minimum temperatures can also be a distinguishing urban heat island (UHI) effect (Hausfather et al. 2013) that can be particularly evident over the summer months (Oke 1982; Karl et al. 1988).

The station data on which nClimDiv divisional data are based have been adjusted for nonclimatic bias with the Menne and Williams (2009) pairwise homogenization (PH) algorithm. Although this algorithm does not explicitly correct for urbanization, Hausfather et al. (2013) demonstrate that it does effectively reduce the difference between U.S. urban and rural temperature trends in monthly USHCN station data. They estimate that, nationally, urban warming effects account for $14 \%-21 \%$ of the increase in unadjusted minimum temperatures during 1895-2010 and 6\%-9\% during 1960-2010. After PH, they found that the algorithm effectively removes UHI biases in minimum temperatures after 1960 and reduces biases before 1930 by $50 \%$. These reductions, however, apply to nationally averaged temperature effects that were calculated from all monthly data during 1895-2010. As a result, they may not reflect the $\mathrm{PH}$ algorithm's effect on regional or seasonal UHI biases. Thus, uncorrected urbanization effects may contribute to some degree to the centennialscale $\mathrm{TMN}_{S}$ trends found in Figs. 3a and 3c, Figs. 5a and 5b, and Fig. 8b. Given Hausfather et al.'s (2013) observation that residual UHI signals not removed by the $\mathrm{PH}$ algorithm are less significant after 1960, and the relatively weak UHI effects on maximum temperatures (Karl et al. 1988; Hausfather et al. 2013), 1970-2015 TMX $_{S}$ trends may be less affected. Barring an analysis similar to that of Hausfather et al. (2013) conducted seasonally over regional spatial scales, however, the magnitude of uncorrected UHI effects on the $\mathrm{TMN}_{S}$ and $\mathrm{TMX}_{S}$ trends found here are uncertain.

The highest-magnitude trends as a percentage of climatology were found in 1970-2015 CDD trends. From an air-conditioning (AC) market survey of U.S. cities during the mid-1990s, Sailor and Pavlova (2003) derived a function that relates annual CDD to municipal-level per capita AC use. This function's nonlinearity [their Eq. (4)] suggests that in cooler regions with climatologically low CDD, modest CDD increases can lead to disproportionate increases in AC use. Thus, $20 \%-40 \% \mathrm{CDD}_{S}$ trends over densely populated northeastern climate divisions (Fig. 8f) may also foreshadow a developing trend toward greater summer electrical consumption. Even larger $(>80 \%) \mathrm{CDD}_{S}$ trends over the Pacific Northwest suggest the possibility of similar trends in Portland, Oregon, and Seattle, Washington, consumption.

In Figs. 8d-f, the strongest $\mathrm{TMX}_{S}, \mathrm{TMN}_{S}$, and $\mathrm{CDD}_{S}$ trends during 1970-2015 are found outside major U.S. agricultural regions, that is, northwestern coastal, interior western, and northeastern climate divisions. Over California's Central Valley (divisions 84 and 87) TMX $_{S}$ trends are insignificant and significant positive $\mathrm{TMN}_{S}$ trend magnitudes are less than $10 \%$ of climatology. However, Central Valley $\mathrm{CDD}_{S}$ trends $(26.2 \%$ and $26.9 \%$ ) are more substantial. Recent $\mathrm{TMX}_{S}$ trends for southern climate divisions are weak $(<3.0 \%)$ or insignificant. Southern $\mathrm{TMN}_{S}$ trends during 1970-2015 are less than $8.4 \%$ of climatology, and $\mathrm{CDD}_{S}$ trend magnitudes are under $20 \%$. Great Plains and midwestern $\mathrm{TMX}_{S}$ and $\mathrm{CDD}_{S}$ trends during 1970-2015 are insignificant and positive $\mathrm{TMN}_{S}$ trends are weak relative to other U.S. regions. In addition, the ORR analyses of $\mathrm{TMX}_{S}$ and $\mathrm{CDD}_{S}$ show no clear regime patterns over midwestern climate divisions since the 1930s (Figs. 4g, 7g). Given the high levels of rank correlation between $\mathrm{CDD}_{S}$ and $\mathrm{GDD}_{S}$ in station data during 1950-2014 (Fig. 6), this 
suggests that $\mathrm{GDD}_{S}$ over this important U.S. growing region has also been stable during the past seven decades.

Estimating agriculturally relevant climate variation from seasonal data has its limitations. Although seasonal variability was emphasized here, temperaturerelated crop stress impacts can occur over submonthly time scales (Suwa et al. 2010). Daily minimum temperature records might better resolve the subseasonal effects of positive $\mathrm{TMN}_{S}$ trends evident over almost all of the continental United States in recent decades. Longterm bias-adjusted daily temperature records could be used to confirm $\mathrm{GDD}_{S}$ variation inferred here from $\mathrm{CDD}_{S}$ data, for example, positive $\mathrm{GDD}_{S}$ trends over California's Central Valley. Daily records could also be useful in studying long-term variation in the length of the U.S. summer growing season. A version of nClimDiv divisional data defined at daily resolution that is currently under development at the NCEI (I. Durre 2017, personal communication) may help to explore these issues in future work.

Acknowledgments. All figures were produced using Generic Mapping Tools (Wessel and Smith 1995). Thanks are given to the reviewers for a number of suggestions that improved the paper. The USDA is an equal opportunity provider and employer.

\section{REFERENCES}

Allen, R. G., L. S. Pereira, D. Raes, and M. Smith, 1998: Crop evapotranspiration: Guidelines for computing crop water requirements. UN Food and Agriculture Organization Irrigation and Drainage Paper 56, 300 pp., http://www.fao.org/docrep/ X0490E/X0490E00.htm.

Butler, E. E., and P. Huybers, 2013: Adaptation of US maize to temperature variations. Nat. Climate Change, $\mathbf{3}, 68-72$, https:// doi.org/10.1038/nclimate1585.

DeGaetano, A. T., 1996: Recent trends in maximum and minimum temperature threshold exceedences in the northeastern United States. J. Climate, 9, 1646-1660, https://doi.org/10.1175/15200442(1996)009<1646:RTIMAM>2.0.CO;2.

— , and R. J. Allen, 2002: Trends in twentieth-century temperature extremes across the United States. J. Climate, 15, 3188-3205, https://doi.org/10.1175/1520-0442(2002)015<3188:TITCTE >2.0.CO;2.

Downton, M. W., T. R. Stewart, and K. A. Miller, 1988: Estimating historical heating and cooling needs: Per capita degree days. J. Appl. Meteor., 27, 84-90, https://doi.org/10.1175/15200450(1988)027<0084:EHHACN $>2.0 . \mathrm{CO} ; 2$.

Duchon, C. E., 1979: Lanczos filtering in one and two dimensions. J. Appl. Meteor., 18, 1016-1022, https://doi.org/10.1175/15200450(1979)018<1016:LFIOAT>2.0.CO;2.

Ebisuzaki, W., 1997: A method to estimate the statistical significance of a correlation when the data are serially correlated. J. Climate, 10, 2147-2153, https://doi.org/10.1175/15200442(1997)010<2147:AMTETS > 2.0.CO;2.

Gallo, K. P., T. W. Owen, D. R. Easterling, and P. F. Jamason, 1999: Temperature trends of the U.S. Historical Climatology Network based on satellite-designated land use/land cover.
J. Climate, 12, 1344-1348, https://doi.org/10.1175/15200442(1999)012<1344:TTOTUS > 2.0.CO;2.

Guanter, L., and Coauthors, 2014: Global and time-resolved monitoring of crop photosynthesis with chlorophyll fluorescence. Proc. Natl. Acad. Sci. USA, 111, E1327-E1333, https:// doi.org/10.1073/pnas.1320008111.

Guttman, N. B., and R. G. Quayle, 1996: A historical perspective of U.S. climate divisions. Bull. Amer. Meteor. Soc., 77, 293-304, https:// doi.org/10.1175/1520-0477(1996)077<0293:AHPOUC>2.0.CO;2.

Hanson, C. L., K. A. Cumming, D. A. Woolhiser, and C. W. Richardson, 1994: Microcomputer program for daily weather simulation in the contiguous United States: USCLIMATE reference manual and user's guide. USDA Agricultural Research Service Publication Rep. ARS-114, 52 pp.

Harris, F. J., 1978: On the use of windows for harmonic analysis with the discrete Fourier transform. Proc. IEEE, 66, 51-83, https://doi.org/10.1109/PROC.1978.10837.

Hausfather, Z., M. J. Menne, C. N. Williams, T. Masters, R. Broberg, and D. Jones, 2013: Quantifying the impact of urbanization on U.S. Historical Climatology Network temperature records. J. Geophys. Res. Atmos., 118, 481-494, https://doi.org/10.1029/2012JD018509.

Hollander, M., and D. A. Wolfe, 1999: Nonparametric Statistical Methods. 2nd ed., John Wiley and Sons, 787 pp.

Karl, T. R., and P. D. Jones, 1989: Urban bias in area-averaged surface air temperature trends. Bull. Amer. Meteor. Soc., 70, 265-270, https:// doi.org/10.1175/1520-0477(1989)070<0265:UBIAAS>2.0.CO;2.

— - G. Kukla, and J. Gavin, 1984: Decreasing diurnal temperature range in the United States and Canada from 1941 through 1980. J. Climate Appl. Meteor., 23, 1489-1504, https://doi.org/ 10.1175/1520-0450(1984)023<1489:DDTRIT>2.0.CO;2.

—, C. N. Williams Jr., P. J. Young, and W. M. Wendland, 1986: A model to estimate the time of observation bias associated with monthly mean maximum, minimum and mean temperatures for the United States. J. Climate Appl. Meteor., 25, 145-160, https:// doi.org/10.1175/1520-0450(1986)025<0145:AMTETT>2.0.CO;2.

_, H. F. Diaz, and G. Kukla, 1988: Urbanization: Its detection and effect in the United States climate record. J. Climate, $\mathbf{1}$, 1099-1123, https://doi.org/10.1175/1520-0442(1988)001<1099: UIDAEI $>2.0 . \mathrm{CO} ; 2$.

— , and Coauthors, 1993: A new perspective on recent global warming: Asymmetric trends of daily maximum and minimum temperature. Bull. Amer. Meteor. Soc., 74, 1007-1023, https:// doi.org/10.1175/1520-0477(1993)074<1007:ANPORG>2.0.CO;2.

— J. T. Melillo, and T. C. Peterson, Eds., 2009: Global climate change impacts in the United States. U.S. Global Change Research Program Rep., 192 pp.

Kunkel, K., L. Stevens, S. E. Stevens, L. Sun, E. Janssen, D. Wuebbles, and J. G. Dobson, 2013: Regional climate trends and scenarios for the U.S. National climate assessment: Part 9. Climate of the contiguous United States. NOAA Tech. Rep. NESDIS 142-9, 77 pp., https://www.nesdis.noaa.gov/sites/ default/files/asset/document/NOAA_NESDIS_Tech_Report_ 142-9-Climate_of_the_Contiguous_United_States.pdf.

Lau, K.-M., and H. Weng, 1995: Climate signal detection using wavelet transform: How to make a time series sing. Bull. Amer. Meteor. Soc., 76, 2391-2402, https://doi.org/10.1175/ 1520-0477(1995)076<2391:CSDUWT >2.0.CO;2.

Lee, J., S. Li, and R. Lund, 2014: Trends in extreme U.S. temperatures. J. Climate, 27, 4209-4225, https://doi.org/10.1175/JCLID-13-00283.1.

Liang, B. C., F. MacKenzie, P. C. Kirby, and M. Remillard, 1991: Corn production in relation to water inputs and heat units. Agron. J., 83, 794-799, https://doi.org/10.2134/agronj1991.00021962008300050004x. 
Lobell, D. B., M. Bänziger, C. Magorokosho, and B. Vivek, 2011: Nonlinear heat effects on African maize as evidenced by historical yield trials. Nat. Climate Change, 1, 42-45, https://doi.org/ 10.1038/nclimate1043.

— , G. L. Hammer, G. McLean, C. Messina, M. J. Roberts, and W. Schlenker, 2013: The critical role of extreme heat for maize production in the United States. Nat. Climate Change, 3, 497501, https://doi.org/10.1038/nclimate1832.

Luo, Q., 2011: Temperature thresholds and crop production: A review. Climatic Change, 109, 583-598, https://doi.org/10.1007/ s10584-011-0028-6.

Mann, H. B., and D. R. Whitney, 1947: On a test of whether one of two random variables is stochastically larger than the other. Ann. Math. Stat., 18, 50-60, https://doi.org/10.1214/aoms/1177730491.

Mauget, S. A., 2003: Multidecadal regime shifts in U.S. streamflow, precipitation, and temperature at the end of the twentieth century. J. Climate, 16, 3905-3916, https://doi.org/10.1175/ 1520-0442(2003)016<3905:MRSIUS>2.0.CO;2.

_- 2004: Low frequency streamflow regimes over the central United States: 1939-1998. Climatic Change, 63, 121-144, https:// doi.org/10.1023/B:CLIM.0000018502.86522.57.

_- 2011: Time series analysis based on running Mann-Whitney $Z$ statistics. J. Time Ser. Anal., 32, 47-53, https://doi.org/10.1111/ j.1467-9892.2010.00683.x.

_ 2015: Optimal ranking regime analysis of TreeFlow dendrohydrological reconstructions. Climate Past, 11, 1107-1125, https://doi.org/10.5194/cp-11-1107-2015.

_ 2018: Reconstructed and projected U.S. residential natural gas consumption during 1896-2043. J. Appl. Meteor. Climatol., 57, 607-625, https://doi.org/10.1175/JAMC-D-17-0155.1.

— to multidecadal U.S. climate variability. Part I: Temperature. J. Climate, 27, 9006-9026, https://doi.org/10.1175/JCLI-D-14-00040.1.

Mederski, H. J., M. E. Miller, and C. R. Weaver, 1973: Accumulated heat units for classifying corn hybrid maturity. Agron. J., 65, 743747, https://doi.org/10.2134/agronj1973.00021962006500050020x.

Meehl, G. A., J. M. Arblaster, and G. Branstator, 2012: Mechanisms contributing to the warming hole and the consequent U.S. east-west differential of heat extremes. J. Climate, 25, 6394-6408, https://doi.org/10.1175/JCLI-D-11-00655.1.

Menne, M. J., and C. N. Williams Jr., 2009: Homogenization of temperature series via pairwise comparisons. J. Climate, 22, 1700-1717, https://doi.org/10.1175/2008JCLI2263.1.

,,-- and R. S. Vose, 2015: United States Historical Climatology Network long-term daily climate records from stations across the contiguous United States. Carbon Dioxide Information Analysis Center, accessed 20 November 2017, http://cdiac.ess-dive.lbl.gov/epubs/ndp/ushcn/daily_doc.html.

Mihovilovic, D., and R. N. Bracewell, 1991: Adaptive chirplet representation of signals on the time-frequency plane. Electron. Lett., 27, 1159-1161, https://doi.org/10.1049/el:19910723.

Minobe, S., T. Manabe, and A. Shouji, 2002: Maximal wavelet filter and its application to bidecadal oscillation over the Northern Hemisphere through the twentieth century. J. Climate, 15, 1064-1075, https://doi.org/10.1175/1520-0442(2002)015<1064: MWFAIA $>2.0 . \mathrm{CO} ; 2$.

Oke, T. R., 1982: The energetic basis of the urban heat island. Quart. J. Roy. Meteor. Soc., 108, 1-24, https://doi.org/10.1002/ qj. 49710845502.

Pan, Z., R. W. Arritt, E. S. Takle, W. J. Gutowski Jr., C. J. Anderson, and M. Segal, 2004: Altered hydrologic feedback in a warming climate introduces a "warming hole." Geophys. Res. Lett., 31, L17109, https://doi.org/10.1029/2004GL020528.
Peng, S., D. R. Krieg, and S. K. Hicks, 1989: Cotton lint yield response to accumulated heat units and soil water supply. Field Crops Res., 19, 253-262, https://doi.org/10.1016/0378-4290(89)90097-X.

Peterson, T. C., X. Zhang, M. Brunet-India, and J. L. VázquezAguirre, 2008: Changes in North American extremes derived from daily weather data. J. Geophys. Res., 113, D07113, https://doi.org/10.1029/2007JD009453.

Portmann, R. W., S. Solomon, and G. C. Hegerl, 2009: Spatial and seasonal patterns in climate change, temperatures, and precipitation across the United States. Proc. Natl. Acad. Sci. USA, 106, 7324-7329, https://doi.org/10.1073/pnas.0808533106.

Quayle, R. G., D. R. Easterling, T. R. Karl, and P. Y. Hughes, 1991: Effects of recent thermometer changes in the Cooperative Station Network. Bull. Amer. Meteor. Soc., 72, 1718-1723, https://doi.org/ 10.1175/1520-0477(1991)072<1718:EORTCI>2.0.CO;2.

Ranson, M., L. Morris, and A. Kats-Rubin, 2014: Climate change and space heating energy demand: A review of the literature. National Center for Environmental Economics Working Paper 14-07, 43 pp., https:/www.epa.gov/sites/production/files/2015-01/documents/ climate_change_and_space_heating_energy_demand.pdf.

Robertson, S. M., S. R. Jeffrey, J. R. Unterschultz, and P. C. Boxall, 2013: Estimating yield response to temperature and identifying critical temperatures for annual crops in the Canadian prairie region. Can J. Plant Sci., 93, 1237-1247, https://doi.org/10.4141/cjps2013-125.

Sailor, D. J., and J. R. Muñoz, 1997: Sensitivity of electricity and natural gas consumption to climate in the U.S.A.-Methodology and results for eight states. Energy, 22, 987-998, https://doi.org/ 10.1016/S0360-5442(97)00034-0.

_ , and A. A. Pavlova, 2003: Air conditioning market saturation and long-term response of residential cooling energy demand to climate change. Energy, 28, 941-951, https://doi.org/10.1016/ S0360-5442(03)00033-1.

Schlenker, W., and M. J. Roberts, 2009: Nonlinear temperature effects indicate severe damages to U.S. crop yields under climate change. Proc. Natl. Acad. Sci. USA, 106, 15 594-15 598, https://doi.org/10.1073/pnas.0906865106.

Seidel, D. J., and J. R. Lanzante, 2004: An assessment of three alternatives to linear trends for characterizing global atmospheric temperature changes. J. Geophys. Res., 109, D14108, https://doi.org/10.1029/2003JD004414.

Suwa, R., and Coauthors, 2010: High temperature effects on photosynthate partitioning and sugar metabolism during ear expansion in maize (Zea mays L.) genotypes. Plant Physiol. Biochem., 48, 124-130, https://doi.org/10.1016/j.plaphy.2009.12.010.

Thom, H. C. S., 1954: The rational relationship between heating degree days and temperature. Mon. Wea. Rev., 82,1-6, https:// doi.org/10.1175/1520-0493(1954)082<0001:TRRBHD>2.0.CO;2.

_ 1966: Normal degree days above any base by the universal truncation coefficient. Mon. Wea. Rev., 94, 461-465, https:// doi.org/10.1175/1520-0493(1966)094<0461:NDDAAB >2.3.CO;2.

USDA, 1994: Major world crop areas and climatic profiles. USDA Agricultural Handbook 664, 279 pp., https://www.usda.gov/ oce/weather/pubs/Other/MWCACP/MajorWorldCropAreas.pdf.

_ 2017a: Agricultural production and prices. USDA Economic Reporting Service, accessed 6 November 2017, https:// www.ers.usda.gov/data-products/ag-and-food-statistics-chartingthe-essentials/agricultural-production-and-prices.

, 2017b: World agricultural production. USDA Foreign Agricultural Service Rep. 10-17, 30 pp., http://usda.mannlib.cornell.edu/ usda/fas/worldag-production//2010s/2017/worldag-production10-12-2017.pdf.

Ventura, V., C. J. Paciorek, and J. S. Risbey, 2004: Controlling the proportion of falsely rejected hypotheses when conducting 
multiple tests with climatological data. J. Climate, 17, 43434356, https://doi.org/10.1175/3199.1.

Vose, R. S., D. R. Easterling, and B. Gleason, 2005: Maximum and minimum temperature trends for the globe: An update through 2004. Geophys. Res. Lett., 32, L23822, https://doi.org/ 10.1029/2005GL024379.

_, and Coauthors, 2014: Improved historical temperature and precipitation time series for U.S. climate divisions. J. Appl. Meteor Climatol., 53, 1232-1251, https://doi.org/10.1175/JAMC-D-13-0248.1.

Wang, B., and Y. Wang, 1996: Temporal structure of the Southern Oscillation as revealed by waveform and wavelet analysis. J. Climate, 9, 1586-1598, https://doi.org/10.1175/ 1520-0442(1996)009<1586:TSOTSO > 2.0.CO;2.

Wessel, P., and W. H. F. Smith, 1995: New version of the generic mapping tools. Eos, Trans. Amer. Geophys. Union, 76, 329, https://doi.org/10.1029/95EO00198.
Wheeler, T. R., P. Q. Craufurd, R. H. Ellis, J. R. Porter, and P. V. V. Prasad, 2000: Temperature variability and the yield of annual crops. Agric. Ecosyst. Environ., 82, 159-167, https:// doi.org/10.1016/S0167-8809(00)00224-3.

Wilks, D. S., 2011: Statistical Methods in the Atmospheric Sciences. 3rd ed. International Geophysics Series, Vol. 100, Academic Press, 704 pp.

2016: "The stippling shows statistically significant grid points": How research results are routinely overstated and overinterpreted, and what to do about it. Bull. Amer. Meteor. Soc., 97, 2263-2273, https://doi.org/10.1175/BAMS-D-1500267.1.

Ye, Q., X. Lin, E. Adee, D. Min, Y. A. Mulisa, D. O’Brien, and I. A. Ciampitti, 2017: Evaluation of climatic variables as yieldlimiting factors for maize in Kansas. Int. J. Climatol., 37, 464475, https://doi.org/10.1002/joc.5015. 